\title{
Article \\ LEA13 and LEA30 Are Involved in Tolerance to Water Stress and Stomata Density in Arabidopsis thaliana
}

\author{
Abigael López-Cordova ${ }^{1}$, Humberto Ramírez-Medina ${ }^{1}$, Guillermo-Antonio Silva-Martinez ${ }^{1}(\mathbb{D}$, \\ Leopoldo González-Cruz $^{1}{ }^{(0)}$, Aurea Bernardino-Nicanor ${ }^{1}{ }^{(0)}$, Wilson Huanca-Mamani ${ }^{2} \mathbb{C}$, Víctor Montero-Tavera ${ }^{3}$, \\ Andrea Tovar-Aguilar ${ }^{4}$, Juan-Gabriel Ramírez-Pimentel ${ }^{5}{ }^{\circledR}$, Noé-Valentín Durán-Figueroa ${ }^{4}$ and \\ Gerardo Acosta-García $1, * \mathbb{D}$
}

1 Departamento de Ingeniería Bioquímica, Tecnológico Nacional de México/IT de Celaya, Antonio García Cubas Pte. \#600 esq. Av. Tecnológico, Celaya 38010, Guanajuato, Mexico; abigael_cordova@hotmail.com (A.L.-C.); hramirez@conacyt.mx (H.R.-M.); guillermo.silva@itcelaya.edu.mx (G.-A.S.-M.); leopoldo.gonzalez@itcelaya.edu.mx (L.G.-C.); aurea.bernardino@itcelaya.edu.mx (A.B.-N.)

2 Departamento de Producción Agrícola, Facultad de Ciencias Agronómicas, Universidad de Tarapacá, Arica 1000000, Chile; whuanca@yahoo.com

3 Biotechnology Department, National Institute for Forestry Agriculture and Livestock Research (INIFAP), Celaya 38110, Guanajuato, Mexico; montero.victor@inifap.gob.mx

check for
updates

Citation: López-Cordova, A.; Ramírez-Medina, H.; Silva-Martinez, G.-A.; González-Cruz, L.; BernardinoNicanor, A.; Huanca-Mamani, W.; Montero-Tavera, V.; Tovar-Aguilar, A.; Ramírez-Pimentel, J.-G.;

Durán-Figueroa, N.-V.; et al. LEA13 and LEA30 Are Involved in Tolerance to Water Stress and Stomata Density in Arabidopsis thaliana. Plants 2021, 10, 1694. https://doi.org/10.3390/ plants10081694

Academic Editors: Francisco Javier Cano Martin and Fermin Morales

Received: 9 June 2021

Accepted: 10 August 2021

Published: 18 August 2021

Publisher's Note: MDPI stays neutral with regard to jurisdictional claims in published maps and institutional affiliations.

Copyright: (c) 2021 by the authors. Licensee MDPI, Basel, Switzerland. This article is an open access article distributed under the terms and conditions of the Creative Commons Attribution (CC BY) license (https:// creativecommons.org/licenses/by/ $4.0 /)$.
4 Instituto Politécnico Nacional, Unidad Profesional Interdisciplinaria de Biotecnología, Av. Acueducto S/N., Col. Barrio La Laguna Ticomán, México City 07340, Mexico; andrea.tovar.aguilar@gmail.com (A.T.-A.); nduranf@ipn.mx (N.-V.D.-F.)

5 Tecnológico Nacional de México/I.T. Roque, km 8 Carretera Celaya-Juventino Rosas, Celaya 38110, Guanajuato, Mexico; garamirez@itroque.edu.mx

* Correspondence: gerardo.acosta@itcelaya.edu.mx; Tel.: +52-4616117575 (ext. 5471)

Abstract: Late embryogenesis abundant (LEA) proteins are a large protein family that mainly function in protecting cells from abiotic stress, but these proteins are also involved in regulating plant growth and development. In this study, we performed a functional analysis of LEA13 and LEA30 from Arabidopsis thaliana. The results showed that the expression of both genes increased when plants were subjected to drought-stressed conditions. The insertional lines lea13 and lea30 were identified for each gene, and both had a T-DNA element in the regulatory region, which caused the genes to be downregulated. Moreover, lea13 and lea30 were more sensitive to drought stress due to their higher transpiration and stomatal spacing. Microarray analysis of the lea13 background showed that genes involved in hormone signaling, stomatal development, and abiotic stress responses were misregulated. Our results showed that LEA proteins are involved in drought tolerance and participate in stomatal density.

Keywords: LEA proteins; stomata density; drought; plant development; stomata development

\section{Introduction}

Abiotic stresses, such as drought, high salinity, heat, cold and freezing, are severe environmental stresses that impair productivity and quality in crop systems and cause extensive losses to agricultural production worldwide because they affect both vegetative and reproductive plant development. However, drought and heat stress usually significantly impact plant reproduction [1,2].

As sessile organisms, plants have developed various sophisticated strategies for adapting to unfavorable environmental changes, including signal transduction to trigger the activation of specific stress-related genes [1,3-5].

One of the response mechanisms used by plants during drought stress is the control of stomata closure to reduce transpiration and, therefore, water loss. During stomata development, there are at least three transcription factors that determine the cell type to be 
differentiated, which are SPEECHLESS (SPCH), MUTE, and FAMA. SPCH regulates the meristemoid mother cell (MMC) transition and asymmetric cell divisions. MUTE regulates meristemoid transition in the guard mother cell (GMC), while FAMA regulates asymmetric divisions that give rise to guard cells (GC) [6]. Additionally, stomatal density and pattern are determined by signals involving the EPIDERMAL PATTERNING FACTORS (EPFs) family, plant hormones, and environmental clues. Because SPCH is early in stomatal development, most act by activating or repressing $\mathrm{SPCH}$, these signals include leucine-rich repeat receptor kinases (LRR-RKs), Cysteine-Rich Receptor-Like Kinases (CRKs), ERECTA (ER), ER-LIKE 1 (ERL1), ERL2, and TOO MANY MOUTHS (TMM) an LRR receptor protein $[7,8]$.

Moreover, late embryogenesis abundant proteins (LEA proteins) are a group of proteins that were first identified in cottonseed (Gossypium hirsutum) and wheat (Triticum aestivum) during the late stages of embryogenesis [1]. They also have been found in other organs in different plants, especially under stress conditions such as cold, high salinity, and drought $[5,9,10]$.

Tobacco plants overexpressing CaLEA6 (from Capsicum annuum) show enhanced tolerance to dehydration and $\mathrm{NaCl}$ but not to colder conditions, as defined by their fresh leaf weights. Therefore, the CaLEA6 protein plays a potential protective role when a water deficit is induced by dehydration and high salinity but not by low temperature [3]. MsLEA4-4 from Medicago sativa was shown to be involved in drought, salt, and oxidative tolerance when it was overexpressed in Arabidopsis plants [11]. MtCAS31 from Medicago trunculata enhances drought tolerance in transgenic Arabidopsis by reducing stomatal density.

From $C$. annuum $\mathrm{cv}$. caballero seeds using differential expression approaches, an $L E A$ gene (CaLEA73) was identified, and its complete cDNA was isolated. CaLEA73 is highly induced in osmopriming treatments, in which $\mathrm{KNO}_{3}$ instead of $\mathrm{GA}_{3}$ was used in combination with PEG [12]. The CaLEA73 gene was ectopically expressed in transgenic $A$. thaliana to analyze its role under drought and salt stresses. The results showed an increase only in drought tolerance in the transgenic lines evaluated [13].

The molecular mechanisms activated when CaLEA73 is overexpressed and the endogenous genes that perform a similar function in Arabidopsis remain unknown. The present study identified two genes, namely At2g18340 and At3g17520, as related to CaLEA73.

Previous reports have suggested the nomenclature for LEA genes. Bies-Ethève et al. [14] named these genes according to how they were placed in different groups and named At2g18340 as AtLEA3-14 and At3g17520 as AtLEA4-3. In total, 51 genes have been found in the Arabidopsis genome that encodes LEA proteins, also named with a number according to their position in the Arabidopsis genome, starting at the top of chromosome 1 [15,16]. Following the above, we named the genes of interest LEA13 (At2g18340) and LEA30 (At3g17520).

Previous reports have shown that $L E A 13$ and $L E A 30$ are involved in the salt stress response and could be in the ABA pathway $[14,16,17]$. A very comprehensive study on the cellular localization of LEA proteins in Arabidopsis found that both LEA13 and LEA30 colocalize in the endoplasmic reticulum and, interestingly, were also observed in vacuoles and the plasma membrane, suggesting they collaborate in similar functions.

Our results indicated that $L E A 13$ and $L E A 30$ are involved in responding to water stress as they are upregulated in wild-type plants under stress conditions. Additionally, $L E A 13$ and LEA30 are required for a proper stomatal density. Physiological studies showed a high transpiration rate, photosynthesis rate, and stomatal conductance in lea13 and lea30 compared to wild-type plants, which caused the loss of water. Stomata development was also affected in lea13 and lea30 lines, as the expression of stomata cell fate markers was affected. 


\section{Results}

\subsection{Identification of Genes Related to CaLEA73}

A search of the Arabidopsis database using the BLAST algorithm was performed to identify sequences related to CaLEA73 and select $L E A$ genes for functional analysis. The analysis allowed the identification of LEA13 and LEA30. Three additional amino acid sequences of the proteins LEA9, LEA42 and LEA43 were compared with CaLEA73 because they had also been reported to be related to LEA13 and LEA30 [15] to increase the robustness of the analysis. Alignment analysis was performed (Figure 1a) to analyze the existence of conserved domains possibly related to their function. The alignment analysis revealed that CaLEA73 and LEA13 shared $40.0 \%$ identity and $66.0 \%$ similarity, CaLEA73 and LEA30 shared $45.7 \%$ identity and $75.7 \%$ similarity and LEA13 and LEA30 shared $36.2 \%$ identity and $58.7 \%$ similarity. Two conserved regions of 37 and 27 amino acids were observed between the sequences, which may be involved in the function of water stress tolerance or stomata development.

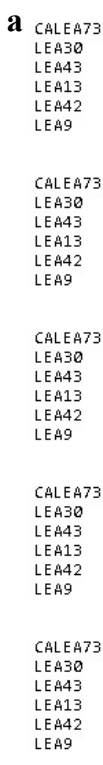

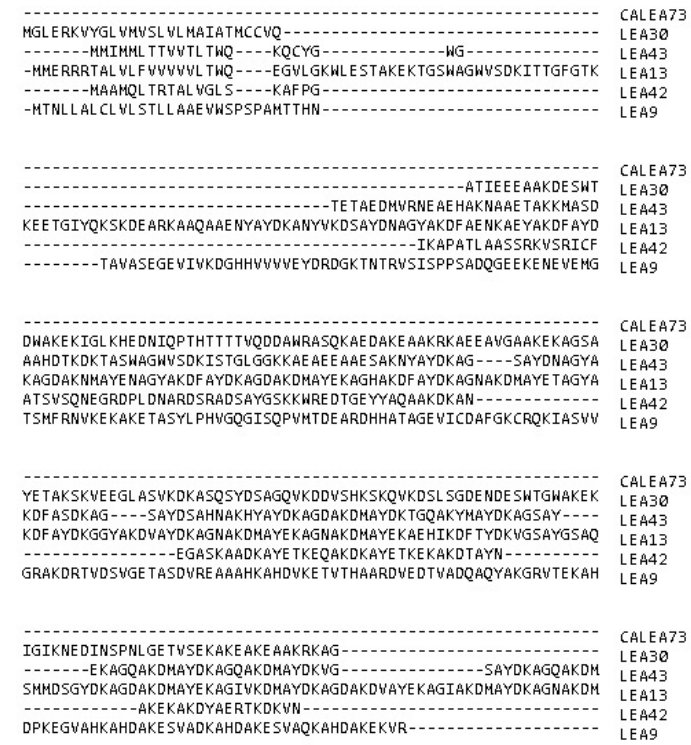

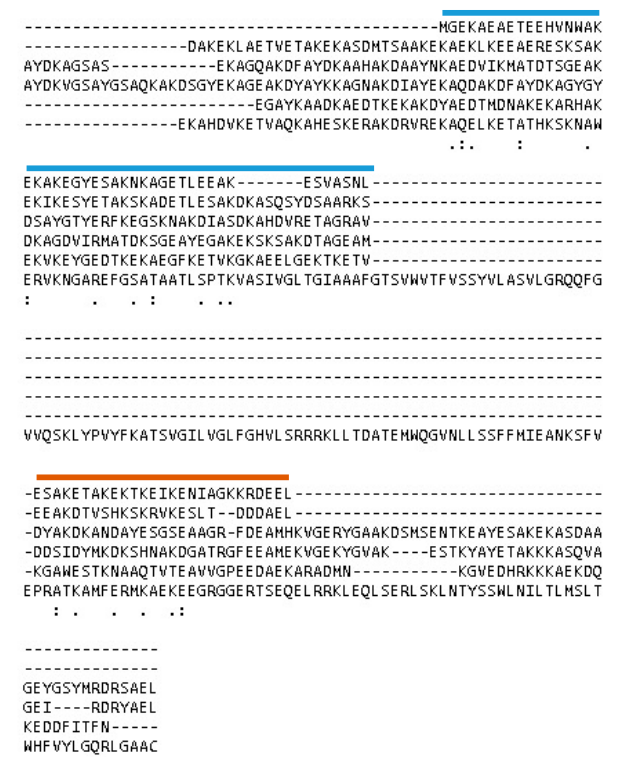

b

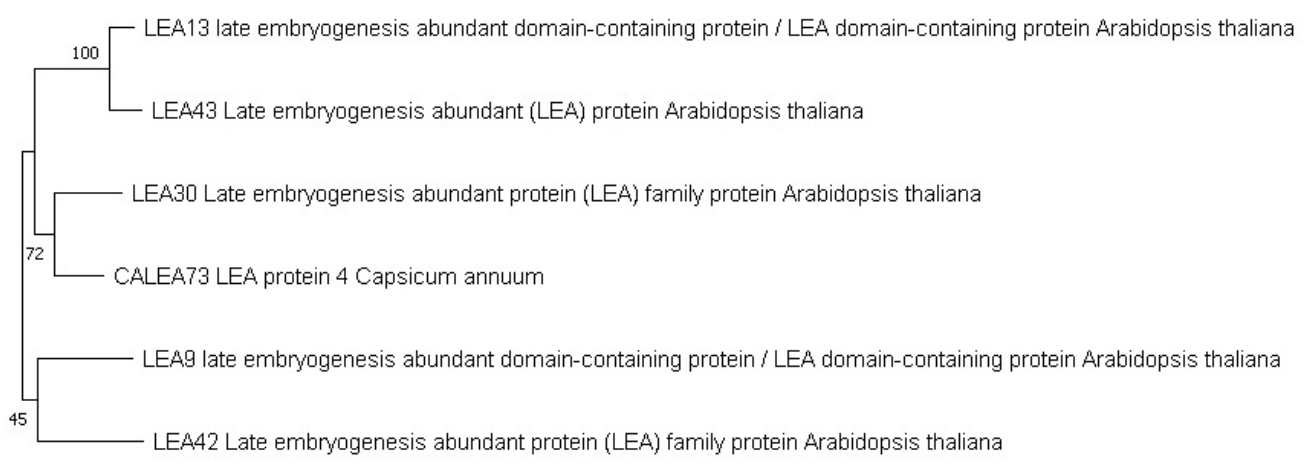

$\mapsto$

0.20

Figure 1. The alignment of the amino acid sequences and phylogenetic relationships between selected proteins and CaLEA73. (a) Amino acid sequences alignment of candidate proteins. They were aligned using the ClustalW program; dashed lines were introduced to maximize sequence alignments. The blue line indicates the first conserved region and the orange line second conserved region. (b). 
A phylogenetic tree was generated to obtain a better idea of how these LEA genes might be related between them (Figure 1b). The result showed that in the same clade of CaLEA73 are LEA13, LEA30, and LEA43, suggesting they may have a similar developmental function.

The phylogenetic tree of amino acid sequences of selected proteins was created. MEGA $X$ software was employed to generate the relationships between five Arabidopsis LEA proteins and the Capsicum annuum protein CaLEA73. The percentage of trees in which the associated taxa clustered together is shown next to the branches.

A comparison of the shared regulatory elements in LEA13 and LEA30 by in silico study was performed to understand the regulatory mechanisms of LEA genes. The $0.5-\mathrm{kb}$ sequences upstream of the translation start site were used as promoters of the LEA13 and LEA30 genes; these were obtained from the TAIR's SeqViewer. The transcriptional response elements in the LEA genes promoters were analyzed using the PLACE database. To determine cis-acting regulatory elements, we queried the sequence of each promoter, analyzed, and identified the presence of various stress-responsive cis-acting regulatory elements, including DRE/CRT, ABRE, LTRE, and MYBS. These stress-responsive elements were relatively abundant in both promoters of the LEA genes, specifically ABRE for LEA13 and DRE for $L E A 30$ (Figure $\mathrm{S1}$ ). These in silico findings suggested responsiveness to abiotic stress for both LEA genes.

\subsection{LEA13 and LEA30 Are Involved in the Tolerance to Water Deficit Stress}

Insertional lines were identified for each gene, lea13 (SALK_004249) and lea30 (SALK_077676), from the Salk Institute database to analyze the function of the LEA13 and $L E A 30$ genes during plant development. The analysis showed that these genes have a T-DNA insertion in the regulatory region (Figure S2).

A water content (WC) analysis was performed to determine how water content changes in lea13 and lea30 mutant plants compared to the wild-type line. For this, insertional lines and wild-type plants were submitted to a drought test for 15 days (Figure S3). During the initial 5 days after withholding water, there was no significant decrease in the amount of plant water neither in the wild-type lines nor lea13 and lea30. Ten days after cessation of irrigation, however, the differences became evident as it was relatively higher in the wild-type (90\%) than in lea13 and lea30 plants (less than 80\%). lea13 plants lost a higher water content than lea30 (Figure S3). When plants grown on soil were subjected to drought stress ( $15 \mathrm{~d}$ of water deprivation), a clear difference in phenotype was observed between lea13, lea30, and wild-type plants (Figure 2). Wild-type plants continued to grow, albeit at a slower rate, whereas lea13 and lea30 exhibited chlorosis and died. Although lea13 plants were more sensitive to drought stress conditions than lea30 plants in rosette leaves, both showed a remarkable delay in growth (Figure 2). In general, lea13 plants showed a more robust phenotype than lea30, and according to phenotypic analysis, LEA13 and LEA30 are implicated in general plant physiology and development. 


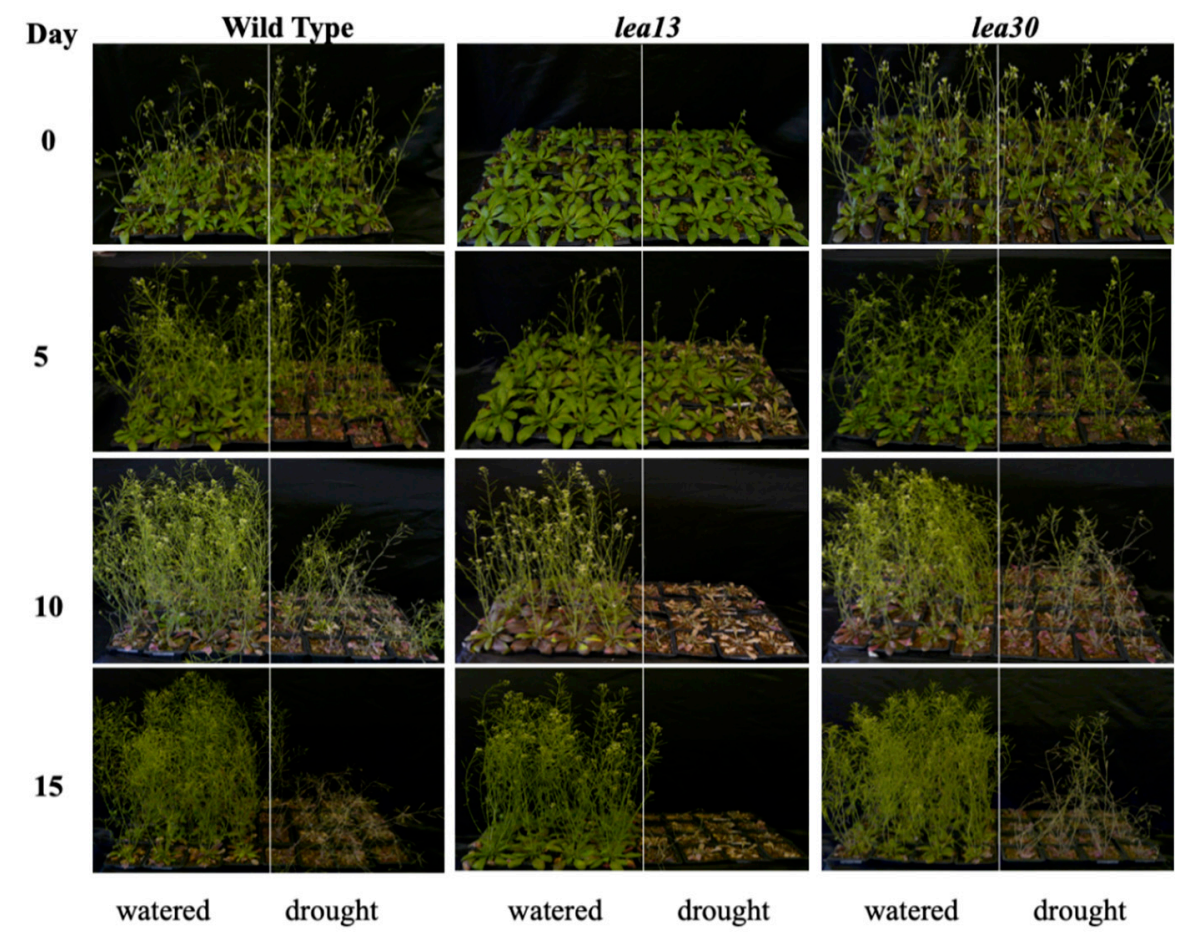

Figure 2. Tolerance to water deficit stress. Six-week-old plants were subjected to water stress, sampled at days $0,5,10$, and 15 after cessation of irrigation, and analyzed for overall plant phenotype. The lea13 and lea30 lines showed greater susceptibility to water stress than the wild-type, which was more evident on day 10. Although all plants were planted and grown in the same space and conditions, the lea13 and lea30 lines showed a delay in development regardless of whether they received irrigation or drought, more pronounced in the lea13 line. Ten plants for each line were used as the experimental unit. Photographs were taken just in the drought stress (Left control plants were well-watered, and on the Right side are plants subjected to drought stress).

\subsection{Expression and Functional Analyses of LEA13 and LEA30 under Water Stress Conditions}

To determine the expression of LEA13 and LEA30 under water stress conditions, 3-wkold plants with no further water addition for $10 \mathrm{~d}$ (drought). The tissue subjected to stress and the control (wild-type plants watered daily) was obtained to perform a quantitative PCR assay using stem, inflorescence, and rosette leaf tissues. We found that the two genes had different patterns of transcript accumulation during tolerance. The relative expression $\left(2^{-\Delta \Delta C T}\right)$ of $L E A 13$ in wild-type plants increased when plants were subjected to drought stress up to 3600-fold for leaf, 9-fold for the stem, and 225-fold for inflorescence. LEA30 also showed an increase during drought to 60-fold for leaf, 110-fold for the stem, and 550-fold for inflorescence (Figure 3). An in silico analysis using 20,000 publicly available RNA-seq libraries [18] for $L E A 13$ and $L E A 30$ was performed (Figure S4). This analysis confirmed that $L E A 13$ and $L E A 30$ are expressed during seed development and lowly in leaf, stem, and flower (Figures S4A and S4B). Interestingly, LEA13 and LEA30 expression is induced upon stress conditions, mostly during drought (Figures S4C and S4D). 
a

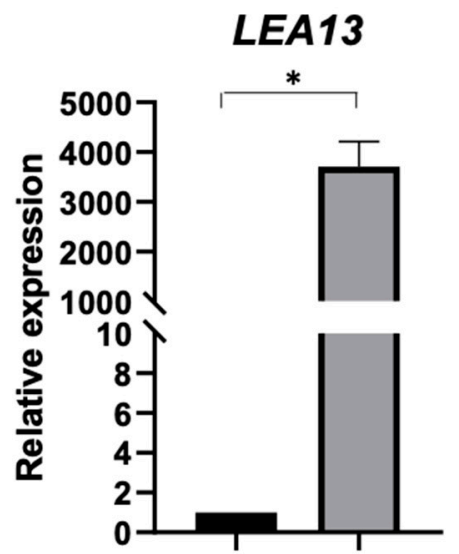

b

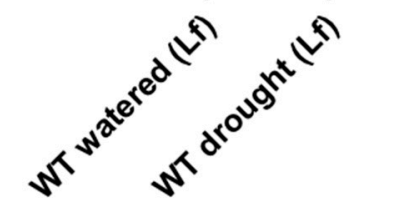

b
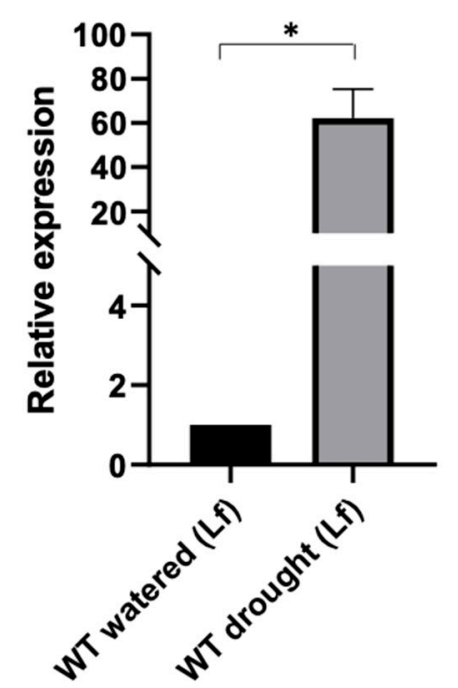

LEA13
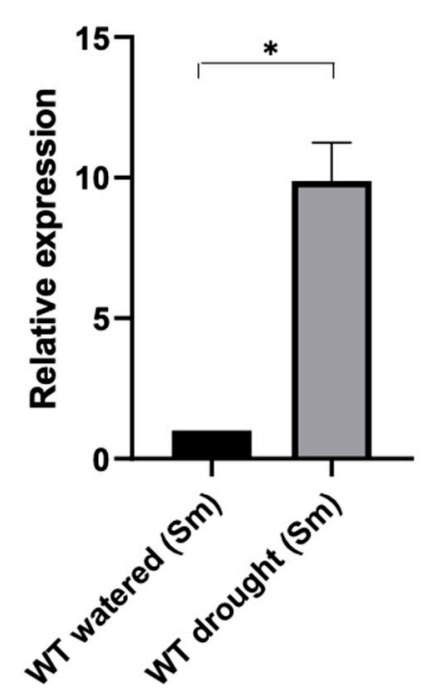

LEA30

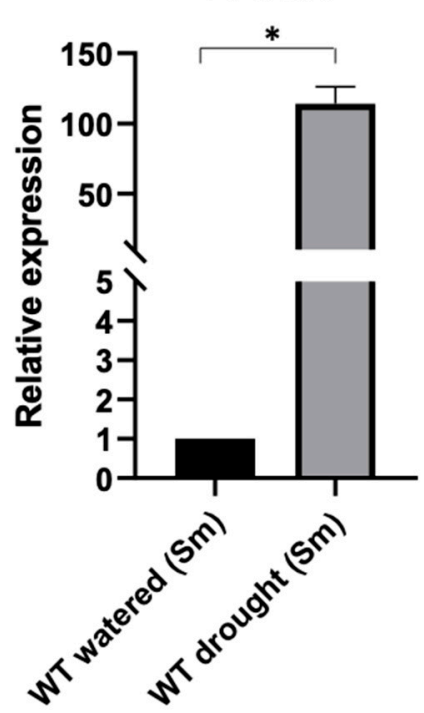

LEA13
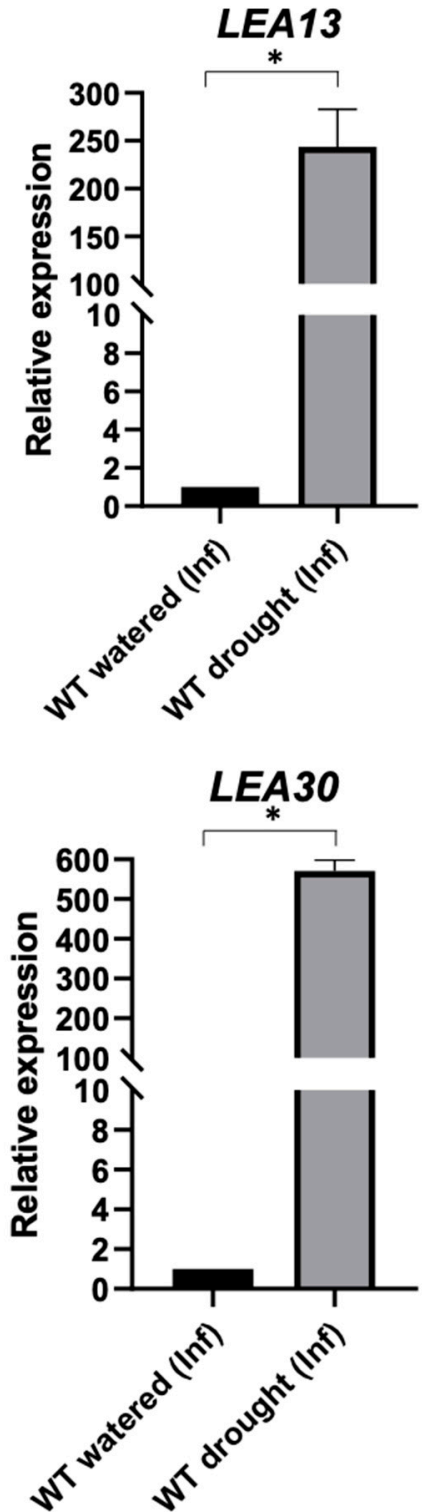

Figure 3. Quantitative RT-PCR analysis of LEA13 (a) and LEA30 (b) on water stress conditions. Wild-type plants of Arabidopsis thaliana were left without watering for ten days, then RNA samples were taken from rosette leaves. Abbreviations: WT (wild-type), Lf (rosette leaf), Sm (stem), and Inf (inflorescence). Y-axis: relative expression $\left(2^{-\Delta \Delta C T}\right)$. ${ }^{*}$ Data represent samples significantly different $p<0.05$. All tests were performed using 3 biological and technical replicates.

A qRT-PCR expression analysis was performed to determine the LEA13 and LEA30 expression in mutant genetic backgrounds. The relative expression LEA13 in the lea13 genetic background decreases significantly for leaf, stem, and inflorescence. The relative expression of LEA30 in the lea30 background also decreases significantly for leaf, stem, and inflorescence (Figure 4a). During drought (ten days after the plants stopped being irrigated), LEA13 expression decreased in lea13 background compared to wild-type (Figure 4b). LEA30 showed similar behavior; in leaf and stem, the expression in the mutant background decreased compared to the wild-type, while in inflorescences tissue, the expression increased (Figure 4c). 
$\mathbf{a}$

LEA13

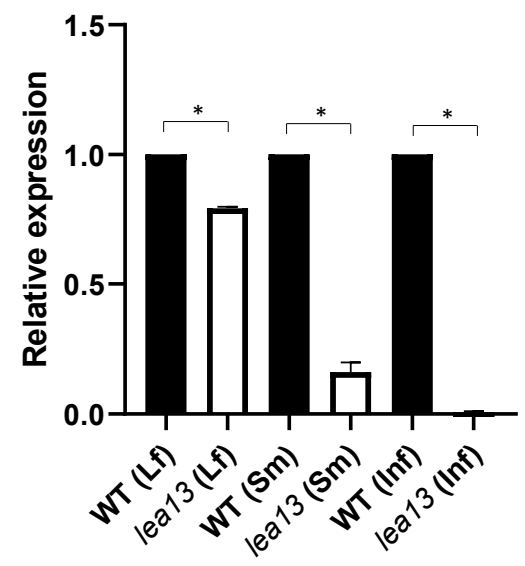

LEA30

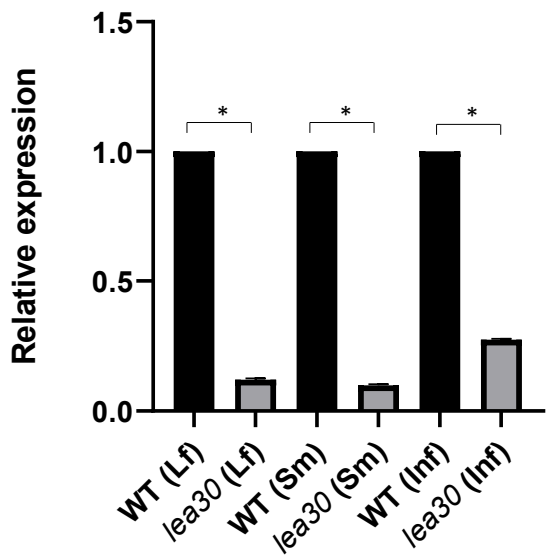

b

LEA13

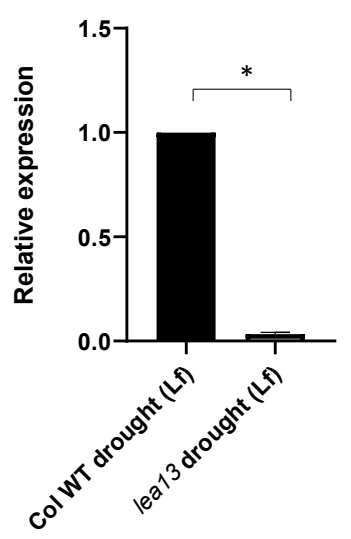

c

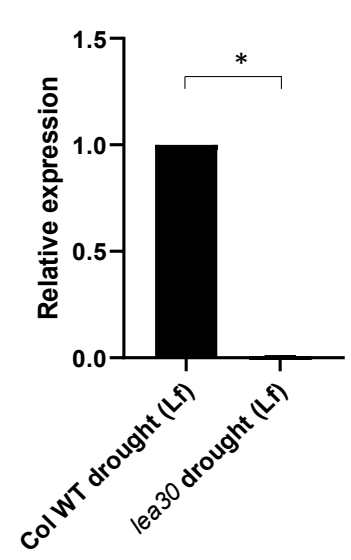

LEA13

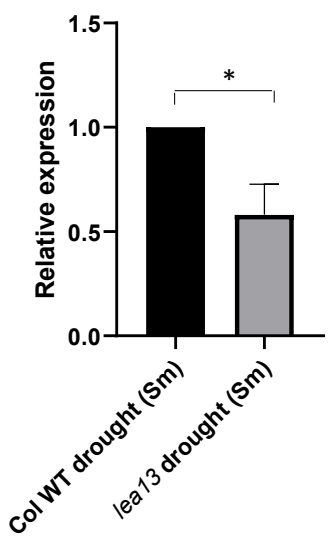

LEA30

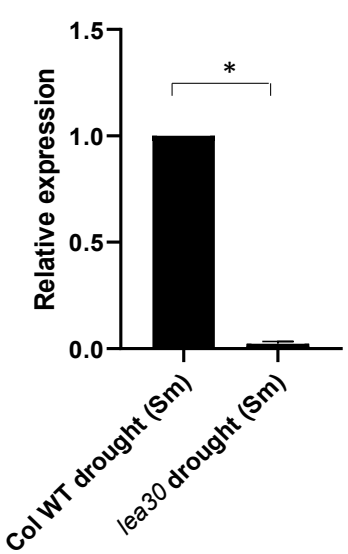

LEA13

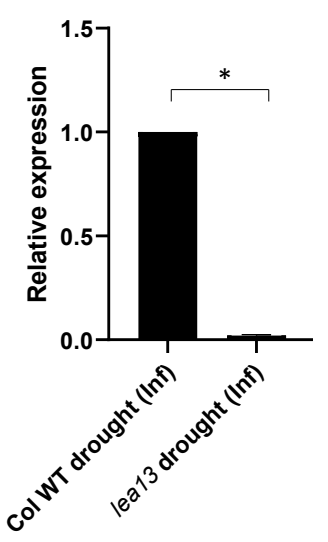

LEA30

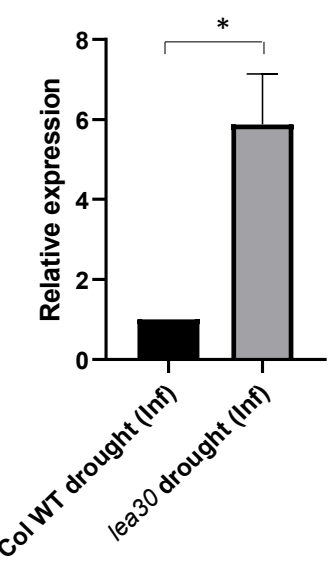

Figure 4. The expression pattern of $L E A 13$ and $L E A 30$ genes in lea13 and lea30 during tolerance to water stress. (a) Relative expression of $L E A 13$ in background lea13 and relative expression of LEA30 in background lea30. (b) Relative expression of LEA13 in background lea13 during tolerance to water stress. (c) The relative expression of LEA30 in background lea30 under water stress conditions. Abbreviations: Sm (stem), Inf (inflorescence), and Lf (rosette leaf). After 10 days of water deficit. Y-axis: relative expression $\left(2^{-\Delta \Delta C T}\right)$. ${ }^{*}$ Data represent samples significantly different $p<0.05$. All tests were performed using 3 biological and technical replicates. 


\subsection{Transpiration and Stomatal Density Are Higher in lea13 and lea30}

Phenotype analysis of cotyledons showed an increase in stomatal density in the mutant lines lea13 and lea30 compared to wild-type (Col-0). Observations on the epidermal surface of cotyledons in the wild-type background showed that stomata are at the mature stage and with a pavement cell separating them (Figure 5a). In the lea13 and lea30 mutants, stomata were also observed at the mature stage; however, the spacing varied (Figure $5 b, c)$. In some areas, clusters of stomata were observed without spacing cells. This phenotype was observed to be stronger in the lea13 background, and the stomata number was higher than in lea30 (Figure 5d). Physiological parameters were measured to analyze the functionality of the stomata. The transpiration rate and stomatal conductance were higher in lea13 and lea30 than in wild-type plants (Figure 6a-b), resulting in increased photosynthesis in lea13 and lea30 compared to that in wild-type plants (Figure $6 \mathrm{c}$ ). These results suggested that $L E A 13$ and $L E A 30$ are involved in the determination of the stomatal patterning and density.
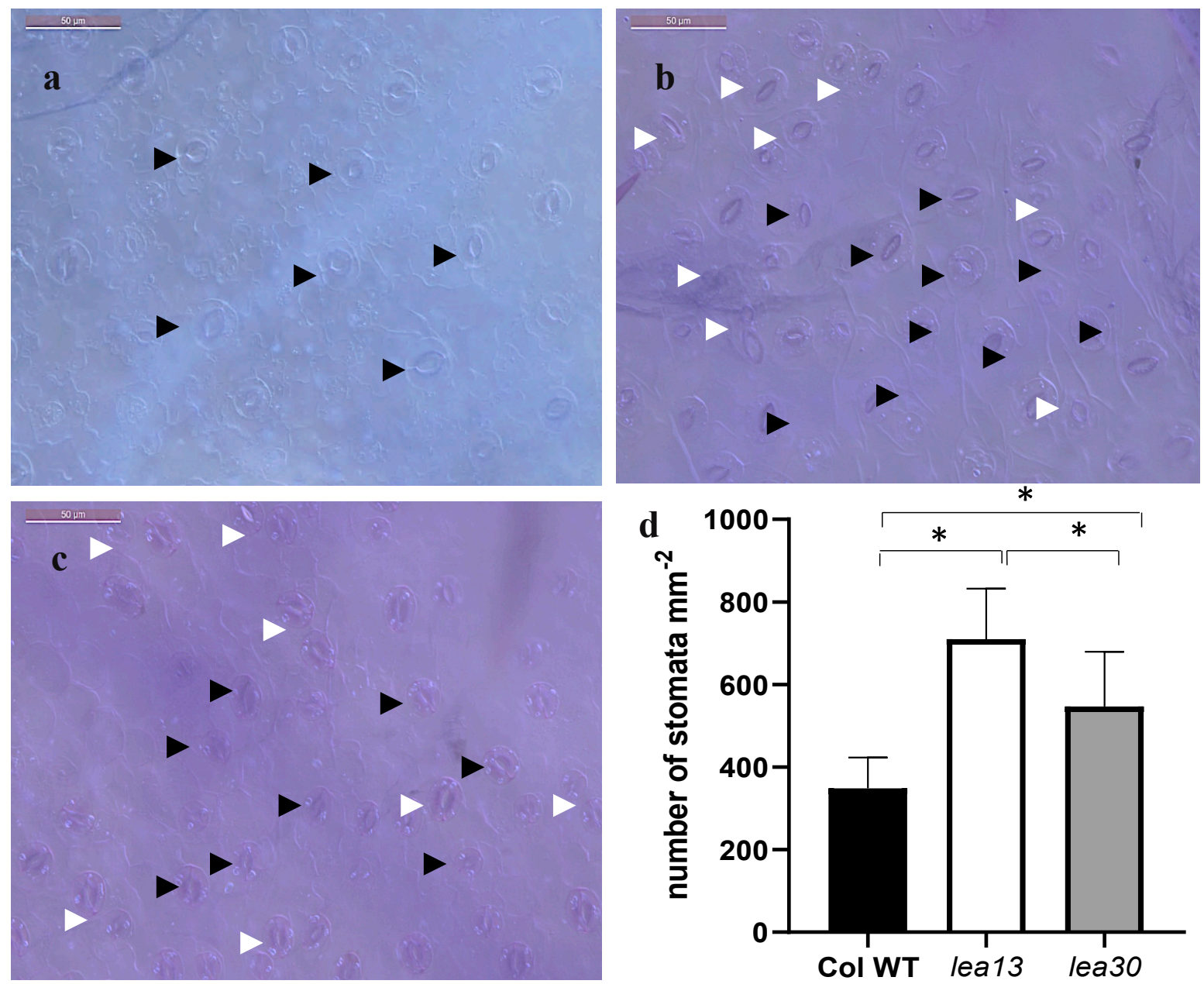

Figure 5. Stomatal density in lea13, lea30, and wild-type plants (a-c). Adaxial sides of cotyledons. Bar, $50 \mu \mathrm{m}$. (a) Wild-type. (b) lea13. (c) lea30. (d) Stomatal density is shown as the average number of stomata per square millimeter. Black arrowheads point mature stomata. White arrowheads point stomata clusters. Bars indicate standard deviation. ${ }^{*}$ Data represent samples Col WT and lea13 significantly different $p<0.05$. ${ }^{* *}$ Data represent samples Col WT and lea30 significantly different $p<0.05$. 

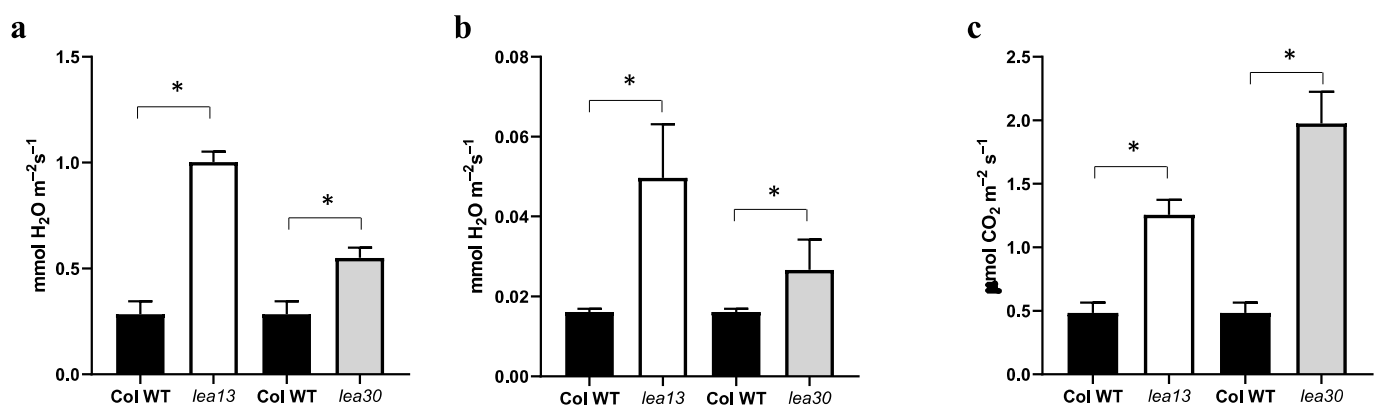

Figure 6. Transpiration, stomatal conductance, and photosynthesis. Rosette leaves of 10 plants of each line were analyzed. (a) Transpiration, (b) Stomatal conductance, and (c) Photosynthesis levels in lea13, lea30, and wild-type plants. The measurements were performed at a temperature of $25^{\circ} \mathrm{C}$ and vapor pressure between 1 and $1.3 \mathrm{kPa}$ with a relative humidity of $70 \%$. Bars indicate standard deviation. * Data represent samples significantly different $p<0.05$.

\subsection{Stomata Developmental Genes Expression Is Affected in the 35S:CaLEA73 Background}

Arabidopsis plants overexpressing the CaLEA73 gene from the Capsicum annuum showed a phenotype of lower stomatal density and higher tolerance to hydric stress than wild-type plants [13]; this phenotype is the opposite to that observed in lea13 and lea30. To determine whether stomata development is affected when LEA protein levels are altered, the expression of cell fate marker genes SPCH, MUTE, FAMA, and TMM, in the stomata of rosette leaves in 35S:CaLEA73 was analyzed (Figure 7). The expression of LEA13 and $L E A 30$ in 35S:CaLEA73 rosette leaves was repressed compared to wild-type. The expression pattern of SPCH and MUTE decreased significantly, but the expression of FAMA and TMM increased significantly in 35S:CaLEA73 (Figure 7). These results suggest that the formation of new stomata has been stopped and that the misregulation of $L E A$ genes alters stomata development.
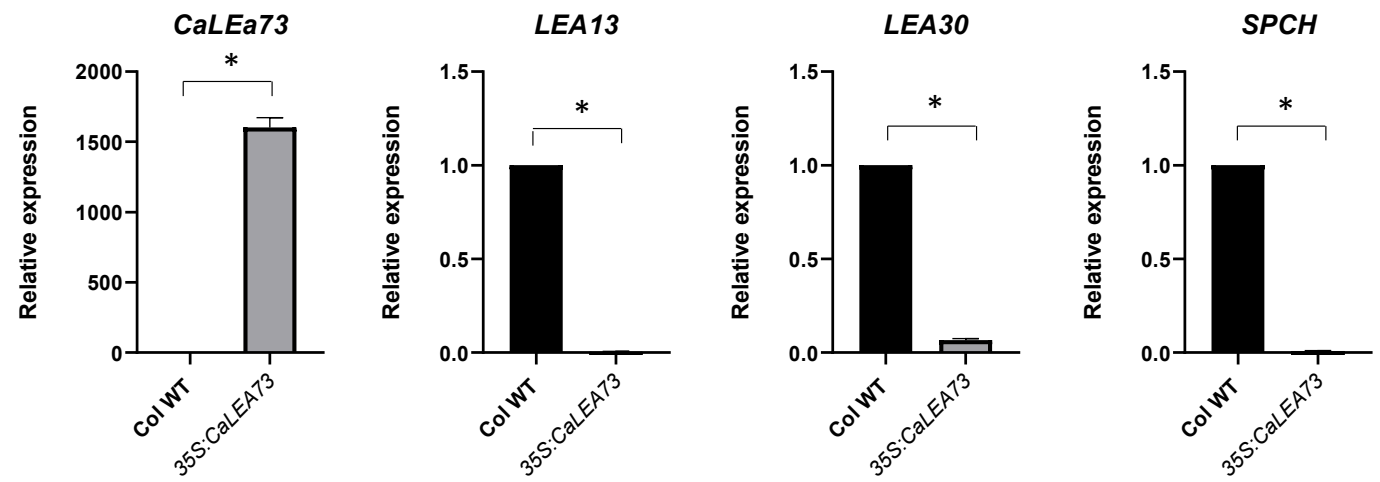

MUTE
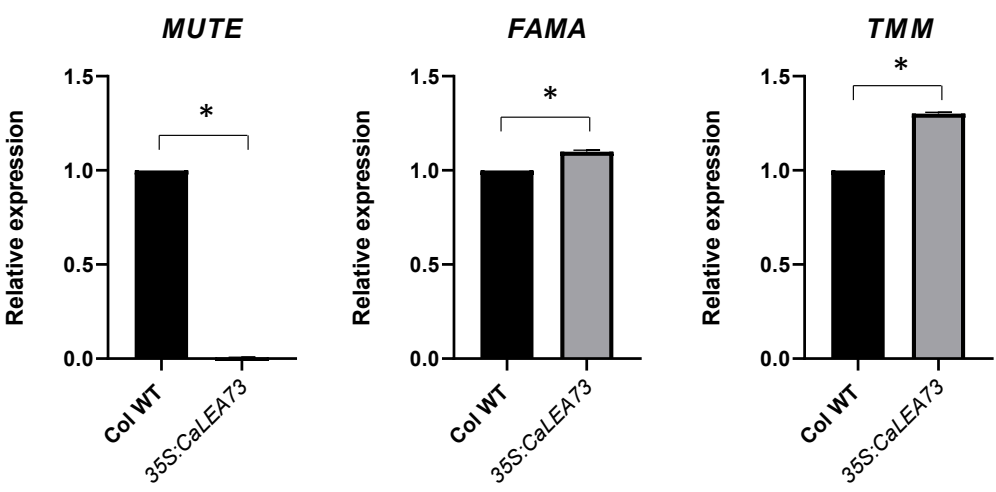

Figure 7. Analysis of the gene expression of lea13, lea30 and markers of stomata development in the 35S:LEA73 genetic background. Cotyledons of seedlings 15 days after germination (dpg) growth under normal irrigation conditions were analyzed. Y-axis: relative expression $\left(2^{-\Delta \Delta C T}\right)$. ${ }^{*}$ Data represent samples significantly different $p<0.05$. All tests were performed using 3 biological and technical replicates. 


\subsection{Differential Gene Expression in lea13}

Because the lea13 line showed a stronger and more consistent phenotype on stomatal density and patterning, we decided to analyze the transcriptional activity in this genetic background in plants grown under normal irrigation conditions, where LEA13 expression is reduced compared to the wild-type background. Microarray analysis showed that 1201 genes were altered more than twofold in the lea13 genetic background (Figure 8), with 589 upregulated genes (Table S1) and 612 downregulated genes (Table S2). Functional gene analysis of misregulated genes showed an enrichment within Gene Ontology (GO) terms corresponding to biological processes such as response to desiccation, response to water deprivation, or response to osmotic stress. However, it also highlights genes related to signaling processes, membrane modification, cell transport, and cell differentiation processes (Figure 8a). In the case of upregulated genes, genes related to drought and osmotic tolerance, transmembrane transport in the cells and organelles are highlighted (Figure $8 \mathrm{~b}$ ). Down-regulated genes were more focused on differentiation processes, cell signaling, hormones, and cell shape and membrane (Figure 8c).

a

b
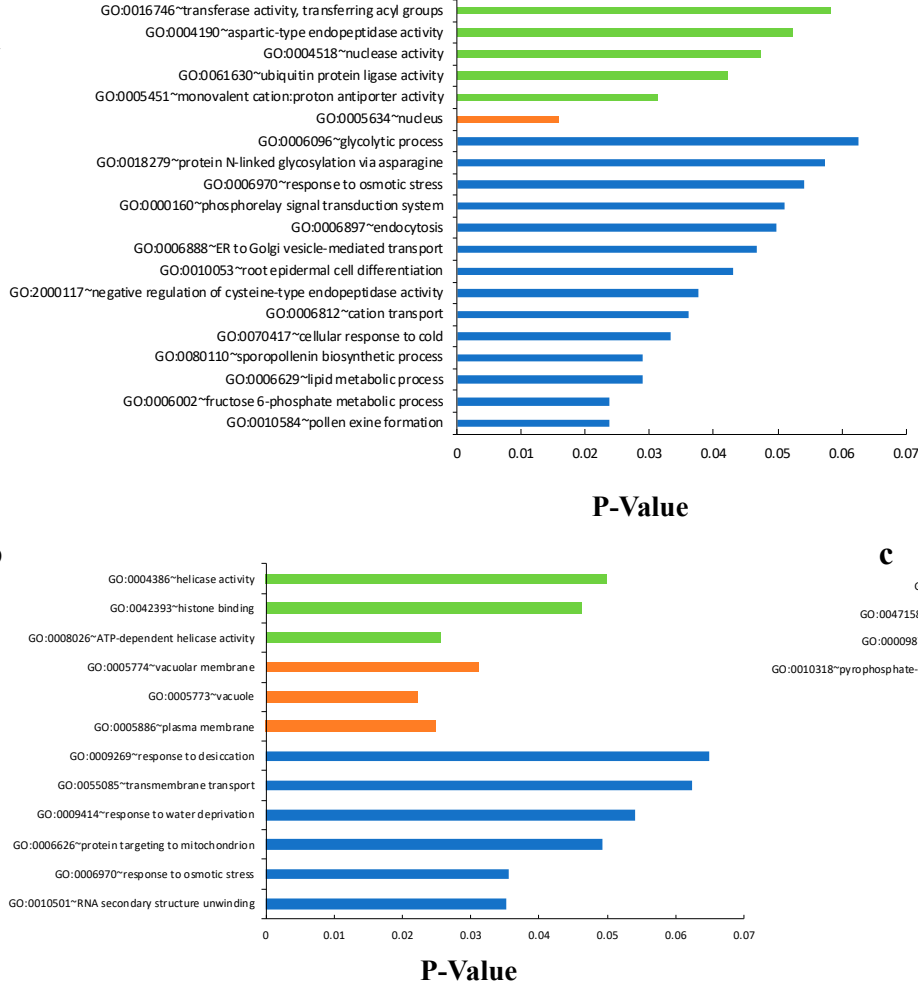

\section{GO Category}

Molecular Function

Cellular component

Biological process

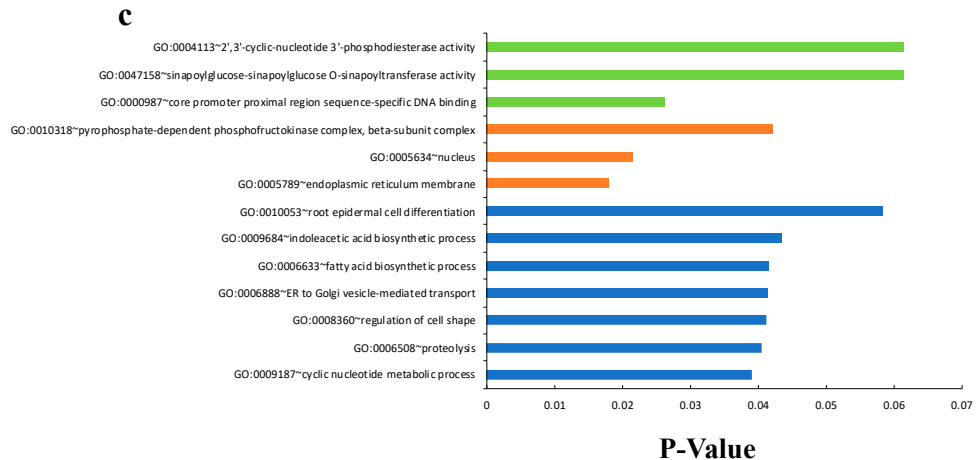

Figure 8. Significantly enriched Gene Ontology (GO) categories (biological process, cellular component, and molecular function): (a) associated with differentially expressed genes from lea13 microarray data, (b) associated with upregulated genes from lea13 microarray data, and (c) associated with downregulated genes from lea13 microarray data. Fisher Exact $p$-Value $=0$ represents perfect enrichment. Usually, $p$-Value is equal to or smaller than 0.05 to be considered strongly enriched in the annotation categories.

\section{Discussion}

Low water availability caused by different environmental conditions, such as drought, salinity, or low temperatures, represents a vulnerable situation for many plants and crops. To contend with and overcome these adverse environments, numerous response mechanisms have been developed by different species of the plant kingdom [19]. LEA proteins are involved in the tolerance to drought stress $[15,20,21]$. On the other hand, there is little information on the participation of LEA proteins in cell differentiation or signaling processes during plant development. 
Based on the previously reported CaLEA73 gene function, $L E A 13$ and $L E A 30$ were identified in the present study. Although CaLEA73 is a very small protein (only 73 amino acids), it shares two domains with selected Arabidopsis LEA proteins [16,20,22-24]. The first domain with 39 amino acids and the second domain with 27 aa, and the region shared among the 5 selected genes (Figure 1). The above suggests that these conserved regions may be involved in drought tolerance and the regulation of stomatal density. In addition, a phylogenetic tree from the amino acid sequences of the candidate proteins established a closer relationship between CaLEA73, LEA13, LEA30, and LEA43. Analysis of the promoter region of $L E A 13$ and $L E A 30$ allowed the identification of stress-responsive cis-acting regulatory elements, mostly ABRE, DRE, MYBS, and LTRE (Figure S1). Most of these cis-elements are involved in the ABA-dependent signaling pathway in response to abiotic stresses.

LEA13 and LEA30 were found to be involved in the plant response to water stress in leaf, stem, and inflorescence tissues. Both genes showed low expression when the plant was not subjected to stress, but their transcript levels increased when plants were under drought stress conditions (Figure 3). LEA13 expression increased more in leaves than in stems or inflorescences, while LEA30 increased in inflorescences than in leaves or stems. The lea13 and lea30 insertional lines contain a T-DNA in the regulatory region, affecting the ABRE and DRE domains interaction (Figure S1-S2), resulting in downregulation of both genes when plants were under normal irrigation conditions (Figure 4). However, when plants were subjected to stress, LEA13 and LEA30 increased their expression in leaves, even in the mutant background (Figure S5), although to a much more limited extent than in the wild-type. The response differed in stem and inflorescence as LEA13 showed higher expression in both tissues in the mutant background than in the wild-type. In the case of $L E A 30$ only in inflorescences, the expression was higher in the lea30 background than in the wild-type. These results suggest that $L E A 13$ and $L E A 30$ may have different regulatory mechanisms and perhaps functions in other tissues. One possibility is that transcription factors can still recognize the ABRE and DRE cis-elements in the insertional lines, but they are different, so the response in terms of expression is different in each tissue.

OsLEA3-1 (from Oryza sativa) has been identified and overexpressed in rice to test the drought resistance of transgenic lines under field conditions. OsLEA3-1 is induced by drought, salt, and abscisic acid (ABA) but not by cold stress, and transgenic rice significantly increases drought resistance [25]. Previous reports have shown that overexpression of CaLEA6 increases tolerance to drought and $\mathrm{NaCl}$ but not too low temperature, suggesting that LEA proteins may be involved in different types of stress tolerance. Dang et al. [26] screened for possible functions of LEA proteins in stress tolerance by expressing 15 genes from A. thaliana in Saccharomyces cerevisiae, and their desiccation stress experiments showed that eight of the 15 LEA proteins significantly enhanced yeast survival $[15,27]$.

Water content analysis showed that the lea13 and lea30 lines lose water content faster than the wild-type, while lea13 showed a higher loss than in lea30; it also was confirmed by phenotyping analysis (Figure 2), confirming that LEA proteins are part of the plant's response mechanism to drought conditions.

$\mathrm{Xu}$ et al. [28] reported that the expression of HVA1, an LEA III family protein in barley, confers tolerance to water deficiency in transgenic rice plants. They reported that constitutive expression of the same protein in transgenic wheat plants improves biomass productivity [28]. Salleh et al. [29] found that AtLEA5, in addition to responding to drought stress conditions, overexpressing lines affect flowering time, shoot biomass, and root length. In addition, it has been reported that the differential of expression of some $L E A$ genes in different tissues suggesting a function during plant development [30].

The integrated response of the whole plant to water deficit must also encompass sensing and signaling mechanisms. The ABA plant hormone is the best-known signal at both the whole plant and cellular levels. ABA can move throughout the plant in the vascular system, and it acts as a signal for changes in stomatal conductance and gene 
expression in response to soil drying. It is now clear that stress responses are dependent on the tissue, cell type and developmental stage of the plant $[1,20]$.

In this study, the downregulation of LEA13 and LEA30 led to increased stomatal density and the transpiration rate, photosynthesis, and stomatal conductance. These latter results suggested an additional function of LEA13 and LEA30 in stomatal density. Moreover, stomata failed to close in the lea13 and lea30 lines. One of the main hormones that have been reported to be involved in stomata closing is ABA [17,31,32]. One hypothesis is that $L E A 13$ and $L E A 30$ are required for the correct function of $A B A$. Previous reports have analyzed several LEA proteins and have found that $L E A 13$ and $L E A 30$ are expressed in most tissues (seed, stem, flower, and leaf) and that LEA30 is induced by ABA treatment [14]. In addition, observations of the adaxial epidermal surface of cotyledons of lea13 and lea30 showed defects in stomata development (Figure 5), as most were at the mature stage, but there were stomatal clusters without the cell spacing that normally allows the correct stomatal patterning.

Acosta-García et al. overexpressed the CaLEA73 gene of $C$. annuum in A. thaliana. The transgenic plants increased drought tolerance due to lower transpiration levels and a lower stomatal density than those in control plants [13]. Thus, these overexpressing lines 35S:CaLEA73 showed a phenotype opposite to that observed in lea13 and lea30, suggesting that high levels of some LEA proteins decrease stomatal density while low levels increase stomatal density. In addition, the MUTE and SPCH stomata genes were downregulated, which agreed with the phenotype of higher stomatal density in lea13 and lea30. While TMM and FAMA increased their expression (Figure 7), these results suggest that asymmetric divisions stopped and decreased the number of stomata. In the lea13 and lea30 lines, where there are low levels of LEA proteins, the phenotype is similar to that of tmm (Figure 5). LEA13 and LEA30 transcripts were reduced and hardly detectable in 35S:CaLEA73 background, which suggests that if there are high levels of this type of LEA protein, the expression of $L E A 13$ and LEA30 is either not required or is downregulated (Figure 5). Nevertheless, low levels of LEA proteins may upregulate the expression of another LEA gene (Figure S6).

We compared gene expression levels in the lea13 T-DNA line using an Arabidopsis whole genome microarray to find genes related to LEA protein function. Differentially expressed genes were identified by comparing the expression profiles of lea13 and Col-0 cotyledons. These genes are misregulated due to LEA13 downregulation can be grouped into 3 main groups, the first one related to stress response, the second one related to stomata development, and the third one related to general plant development, mainly flowering (Figure 8). Interestingly, many of the differentially expressed genes are related to the endoplasmic reticulum where both LEA13 and LEA30 have been localized and may be involved in protein modification under stress conditions. Additionally, genes coding for proteins with DNA binding capacity were observed, which could be related to stomata or plant development processes.

One of the upregulated genes was SAUR-like auxin-responsive protein is a hormonerelated gene (Table 1). By transcriptome analysis, Yang et al. [33] found that SAUR-like is related to xylem differentiation processes and regulating genes involved in cell division processes. Additional experiments will be required to analyze which of these events are involved during stoma development. GSK3/Shaggy kinases are involved in a wide range of fundamental processes in development and metabolism. GSK3/Shaggy kinases have been involved in the response and adaptation to salt stress [34]. Perhaps these proteins are involved in the signaling pathway that LEA proteins activate when plants are subjected to stress conditions. 
Table 1. Up-regulated genes involved in hormones, stomatal development abiotic stress responses.

\begin{tabular}{|c|c|c|c|}
\hline AGI Code & Zscore & Annotation & Description \\
\hline AT1G65440 & 5.243761 & $\begin{array}{l}\text { GLOBAL TRANSCRIPTION FACTOR } \\
\text { GROUP B, global transcription factor } \\
\text { group B1 }\end{array}$ & $\begin{array}{l}\text { Transcription elongation factor SPT6-like } \\
\text { protein }\end{array}$ \\
\hline At1g75590 & 4.204775 & F10A5.20, F10A5_20 & SAUR-like auxin-responsive protein \\
\hline At1g17240 & 4.004409 & $\begin{array}{c}\text { AtRLP2, F20D23.6, F20D23_6, receptor-like } \\
\text { protein } 2\end{array}$ & $\begin{array}{l}\text { Receptor-like protein 2; Encodes a CLAVATA2 } \\
\text { (CLV2)-related gene. }\end{array}$ \\
\hline At4g15040 & 3.362095 & At4g15040 & $\begin{array}{c}\text { Subtilisin-like serine endopeptidase } \\
\text { family protein. }\end{array}$ \\
\hline At2g01420 & 3.242944 & $\begin{array}{c}\text { ARABIDOPSIS PIN-FORMED 4, AUXIN } \\
\text { TRANSPORTER SPLICE VARIANT B, } \\
\text { PIN-FORMED } 4\end{array}$ & Auxin efflux carrier component 4 . \\
\hline At3g05840 & 3.101374 & ASKGAMMA, F10A16.14, F10A16_14 & $\begin{array}{c}\text { Shaggy-related protein kinase gamma; encodes } \\
\text { a SHAGGY-like kinase involved in meristem } \\
\text { organization. }\end{array}$ \\
\hline At4g23270 & 3.003471 & $\begin{array}{l}\text { F21P8.160, F21P8_160, cysteine-rich RLK } \\
\text { (RECEPTOR-like protein kinase) } 19\end{array}$ & Cysteine-rich receptor-like protein kinase 19 \\
\hline At3g62670 & 2.782405 & $\begin{array}{l}\text { ARR20, MEE41, maternal effect embryo } \\
\text { arrest 41, response regulator ARR20 }\end{array}$ & $\begin{array}{l}\text { Putative two-component response regulator } \\
\text { ARR20; response regulator } 20\end{array}$ \\
\hline At1g76520 & 2.556337 & F14G6.12, F14G6_12 & Auxin efflux carrier family protein. \\
\hline At1g65480 & 2.536566 & F5I14.3, F5I14_3, FLOWERING LOCUS T & FLOWERING LOCUS T protein; \\
\hline At2g39540 & 2.342906 & F12L6.20, F12L6_20 & Gibberellin-regulated protein \\
\hline At5g10310 & 2.315854 & F18D22.80, F18D22_80 & Epidermal patterning factor-like protein \\
\hline
\end{tabular}

SPT6-like (SPT6L) is a conserved elongation factor that is associated with phosphorylated RNA polymerase II (RNAPII) during transcription (Table 1). Chen et al. [35] mentioned two versions of SPT6: SPT6 and SPT6-like (SPT6L) in Arabidopsis. The transcript of SPT6 is poorly detected in most tissues, and mutants do not show an obvious phenotype. SPT6L is involved in determining the apical-basal axis and embryonic development. Therefore, SPT6L may be involved in the asymmetric divisions that occur during stomata development.

Members of the plant-specific gibberellic acid-stimulated Arabidopsis (GASA) gene family play roles in hormone responses, defense, and flower development. Gibberellins have been reported to participate in many biological processes, including cell differentiation [36]. Gibberellins are related to stomata formation in Arabidopsis hypocotyls and cell division [37], and they participate in the processes of plant transpiration and drought tolerance [22]. EPIDERMAL PATTERNING LIKE (EPFL) encodes peptides involved in plant development, which decrease stomatal density when overexpressed [38,39]. These findings match the stomatal density observed in both lea13 and lea30.

Another gene that has attracted attention is the FLOWERING LOCUS T (FT) gene, which has been shown to modulate ambient temperature-responsive flowering in Arabidopsis [40]. An interesting phenotype observed in lea13 and lea30 was a delay in the development and flowering of the plant. This delay may have been due to the expression of the FT signaling pathway being affected. However, to confirm this, additional experiments are required.

Transcription factors were also found in the downregulated genes (Table 2), including NAC9, AINTEGUMENTA-like 7, MYB, bHLH123, and AGAMOUS-like 93, which participate in different developmental programs, such as floral development, cell division, lateral root development, senescence, secondary cell wall synthesis, abiotic stress responses, and biotic stress responses [41-44]. In Arabidopsis, FLP1 and MYB88 encode two paralogous R2R3-MYB proteins, which involves establishing stomatal patterning by permitting only a single symmetric division before stomata differentiate and in the control of abiotic stress responses [45]. Double mutant flp1 myb88 produce plants with abnormal stomata development are more susceptible to drought and salinity stress and have increased water loss than WT plants $[45,46]$. Similar phenotypes are described to lea13 and lea30. When 
overexpressed, these transcription factors reveal their relationship with the phytohormone auxin, auxin is a plant hormone that widely regulates plant development, but its role in stomatal development was reported only recently. An interesting time-lapse experiment reveals that auxin activity changes over stomatal development. Auxin activity is high in the early stages but depleted from GMCs [8]. This result could explain the growth and flowering delay in the lines lea13 and lea30.

Table 2. Down-regulated genes involved in hormones, stomatal development abiotic stress responses.

\begin{tabular}{|c|c|c|c|}
\hline AGI Code & Zscore & Annotation & Description \\
\hline AT4G35580 & -6.65111 & $\begin{array}{c}\text { F8D20.90, F8D20_90, NAC transcription } \\
\text { factor-like } 9\end{array}$ & NAC transcription factor-like 9. \\
\hline At5g65510 & -4.88908 & $\begin{array}{c}\text { AT5G65510, AINTEGUMENTA-like 7, } \\
\text { PLETHORA 7, PLT7 }\end{array}$ & $\begin{array}{c}\text { AINTEGUMENTA-like } 7 \text { protein; Encodes one } \\
\text { of three PLETHORA transcription factors } \\
\text { required to maintain high levels of PIN1 } \\
\text { expression. }\end{array}$ \\
\hline At3g61900 & -4.14811 & AT3G61900 & SAUR-like auxin-responsive protein. \\
\hline At2g06020 & -3.48404 & At2g06020 & $\begin{array}{l}\text { Myb family transcription factor; } \\
\text { Homeodomain-like superfamily protein. }\end{array}$ \\
\hline At5g26950 & -3.45455 & $\begin{array}{l}\text { AT5G26950, AGAMOUS-like 93, F2P16.17, } \\
\text { F2P16_17 }\end{array}$ & Agamous-like MADS-box protein AGL93. \\
\hline At3g20640 & -3.19807 & AT3G20640 & Transcription factor bHLH123. \\
\hline At5g40330 & -3.18796 & transcription factor MYB23 & $\begin{array}{l}\text { MYB DOMAIN PROTEIN 23, myb domain } \\
\text { protein 23; Encodes a MYB gene that, when } \\
\text { overexpressed ectopically, can induce ectopic } \\
\text { trichome formation. }\end{array}$ \\
\hline At1g26945 & -3.06999 & AT1G26945, KIDARI & $\begin{array}{l}\text { Basic helix-loop-helix protein KIDARI; basic } \\
\text { helix-loop-helix (bHLH) DNA-binding } \\
\text { superfamily protein KIDARI (KDR). }\end{array}$ \\
\hline At3g18040 & -3.05605 & AT3G18040, MAP kinase 9 & Mitogen-activated protein kinase 9. \\
\hline At1g01260 & -3.02189 & AT1G01260, F6F3.7, F6F3_7 & Transcription factor bHLH13. \\
\hline At3g25905 & -2.89363 & CLAVATA3/ESR-RELATED 27, CLE27 & $\begin{array}{c}\text { Protein CLAVATA3/ESR-related 27; Member } \\
\text { of a large family of putative ligands } \\
\text { homologous to the Clavata3 gene. }\end{array}$ \\
\hline At5g58890 & -2.82425 & AGAMOUS-like 82, K19M22.9, K19M22_9 & Protein AGAMOUS-LIKE 82. \\
\hline
\end{tabular}

Wurzinger et al. [47] mentioned that AtMPK9 (At3g18040) and AtMPK12, which are preferentially and highly expressed in guard cells, also function as positive regulators of stomatal closure. The CLAVATA3/ESR (CLE)-related genes have been suggested to regulate meristem maintenance and the undifferentiated state $[48,49]$. A possible explanation for the increased transpiration in the lea13 and lea30 lines is that the closure of the stomata is inactive, as these could be involved in the processes of stomata differentiation.

Kanaoka et al. [50] reported that the ICE1 protein forms a dimer with these transcription factors to regulate stomatal development. Genes related to helix-base (bHLH), namely, SPCH, MUTE, and FAMA, are positive regulators of entry into the stomatal cell linage, transition from the meristem to $C M G$, and terminal differentiation of guard cells, respectively [23,24,50-54]. These expression changes suggest that altered LEA13 and LEA30 expression affect stomatal density and development by modifying the expression of key genes for stomata development. In the case of the role of LEA proteins in determining stomatal density, based on the results obtained in this study and previously reported, we hypothesized (Figure 9) that under certain stress conditions, LEA13 and LEA30 can activate directly or indirectly on MYB proteins such as FLP1 or MYB88 and some cyclins for modulation of cell divisions. Another possibility is that low levels of LEA proteins also activate EPF1, a peptide secreted from later stomatal lineage cells (late meristemoids and GMCs), which is perceived by a receptor complex consisting of ERL1, TMM, and SERKs in neighboring meristemoids, which prevents the meristemoid from producing stomata next to the existing stomata. In both cases, in lea13 or lea30 mutant, the interaction with 
these proteins is altered, giving rise to defects in stomatal development and activating a mechanism to increase stomatal density $[39,55,56]$.

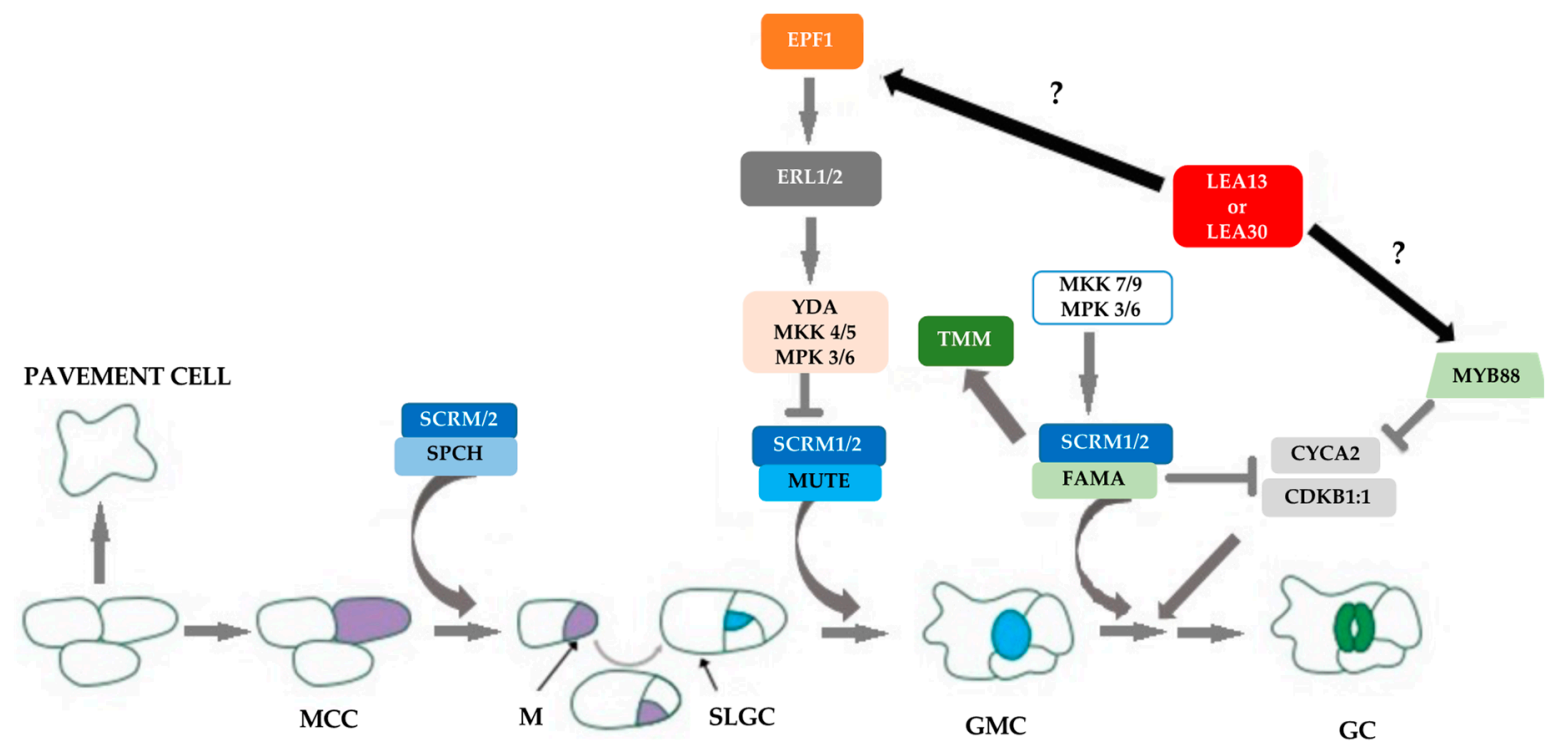

Figure 9. The hypothetical role of LEA proteins during stomatal development in Arabidopsis. A part of the protodermal cells acquires the character of meristemoid mother cells (MMCs); the MMC undergoes asymmetric cell division and gives rise to a meristemoid (M) and a stomatal lineage ground cell (SLGC). Meristemoids can undergo asymmetric amplifying divisions before differentiating into a guard mother cell (GMC). GMC undergoes symmetric division to form a pair of guard cells (GC), forming SCRM1 or SCRM2, playing essential roles in the respective key steps, as indicated by arrows. FLP1 and MYB88 are MYB transcription factors that regulate key fate transitions during stomatal development. LEA13 and LEA30 can both activate directly or indirectly on FLP1/MYB88 and some cyclins for modulation of cell divisions or EPF1, a peptide secreted from meristemoids and GMC cells, is perceived by a receptor complex consisting of ERL1, TMM, and SERKs, which prevents the meristemoid from producing stomata next to the existing stoma.

In addition, LEA protein levels may influence the expression of other LEA genes and plant developmental genes, allowing plants to have a faster response, which includes activation of water stress response genes, plant development, and stomatal density.

\section{Materials and Methods}

\subsection{Plant Materials and Growth Conditions}

T-DNA insertion alleles for LEA13 (SALK_004249; lea13) and LEA30 (SALK_077676; lea30) were obtained from the Arabidopsis Biological Resources Center (ABRC) at Ohio State. Arabidopsis thaliana plants ecotype Columbia-0 (Col-0) was used as wild-type in all studies unless otherwise noted. The T-DNA lines were confirmed by PCR-based genotyping using primers designed by primer BLAST. The following primers were used: LEA13-F (5'-TTTATCACCAGAGAATCAGAC-3'); LEA13- $R$ (5'-TTTCCTCTTGCCACGTCAACA-3'); LEA30- $F$ (5'-TTGGACACAACACATCGT-3'); and LEA30-R (5'-GAAGATCGGAAATCAT CA-3'). Plants were initially grown on Murashige and Skoog (MS) agar plates in a plant growth chamber (Lab-line biotronette-model) with $16 \mathrm{~h}$ light $/ 8 \mathrm{~h}$ dark cycles for 10 days at $23{ }^{\circ} \mathrm{C}$. Then, seedlings were transferred to pots containing substrate (peat moss: perlite: vermiculite 3:1:1 v/v) in a greenhouse with natural light (PAR of $140 \mu \mathrm{mol} \mathrm{m}{ }^{-2} \mathrm{~s}^{-1}$ ) at $25{ }^{\circ} \mathrm{C}$ with an average maximum and minimum relative humidity of $80 \%$ and $60 \%$, respectively.

\section{Sequence Alignments}

The three LEA proteins, namely, LEA13 (At2g18340), LEA30 (At3g17520), and CaLEA73, were selected for amino acid sequence alignment by Clustal Omega software (https: //www.ebi.ac.uk/Tools/msa/clustalo/). The phylogenetic tree was inferred by using the 
Maximum Likelihood method and General Reverse Transcriptase + Freq. model [57]. The tree with the highest $\log$ likelihood (-4625.43), based on 100 bootstraps, is shown. This analysis involved 6 amino acid sequences. All these analyses were conducted in MEGA $\mathrm{X}$ [58].

\subsection{Promoter cis-Element Analysis}

The promoter sequences ( $0.5 \mathrm{~kb}$ upstream of the translation start site) of all LEA genes were obtained from The Arabidopsis Information Resource (TAIR) (https: / / www. arabidopsis.org/). The transcriptional response elements in the LEA gene promoters were predicted using the PLACE database (https:/ / www.hsls.pitt.edu/obrc/index.php?page= URL1100876009).

\subsection{Drought Tolerance Experiments and Determination of Water Content}

Seeds of wild-type (Col-0 ecotype), lea13, and lea30 lines were grown as mentioned above. Three-week-old plants were transferred to a chamber at $23{ }^{\circ} \mathrm{C}$ with no further water addition for $15 \mathrm{~d}$ (drought) to determine the expression of LEA13 and LEA30 genes under water stress conditions. Control wild-type and mutant plants were watered daily. The tissue was obtained from 10 drought-stressed plants and 10 normally irrigated plants on days 0 and 15. Water Content (WC) was determined as follows: 3 rosette leaves of each plant by treatment were excised, and their fresh weight was scored immediately. Leaves were then dried in an oven at $70{ }^{\circ} \mathrm{C}$ overnight and weighed. The Water Content was calculated as follows (Equation (1)):

$$
W C=\frac{(\text { freshweight }- \text { dryweight })}{\text { freshweight }} \cdot 100
$$

\subsection{Gene Expression Analysis by qRT-PCR}

To test the expression levels of LEA13 (At2g18340), LEA30 (At3g17520), and AtUBC10 (AT5G53300), an internal control $[59,60]$ using qRT-PCR, total RNA was extracted using TRIzol reagent according to the manufacturer's instructions (Invitrogen, MX). The RNA concentration was checked using a NanoDrop 2000 spectrophotometer. Approximately $500 \mathrm{ng}$ of total RNA was used for cDNA synthesis reactions using the ProtoScript ${ }^{\circledR}$ II First Strand cDNA Synthesis Kit (BioLabs). The primers for LEA13, LEA30, CaLEA73, and AtUBC10 were designed with Primer Express v.2.0 (Applied Biosystems) (Table S1).

The absence of nonspecific products and primer dimers was confirmed by analyzing the amplicons' melt curves and electrophoretic gel analysis. The cDNA templates and primers were added to SYBR GREEN/ROX qPCR PCR Master Mix (Thermo Scientific). qRT-PCR was performed with three biological and technical replicates using an $\mathrm{Eco}^{\mathrm{TM}}$ Illumina Real-Time PCR System, and the data were analyzed using the corresponding EcoStudy Software v5.0 program and normalized using the AtUBC10 gene as internal control. All data were analyzed using Student's $t$-test.

\subsection{Analysis of Stomatal Development}

Epidermal phenotypes were also determined on tissue cleared in $6 \%$ sodium hypochlorite for $2 \mathrm{~h}$ and stained with toluidine blue for $15 \mathrm{~min}$. Images were captured from cotyledons of seedlings at 15 days post-germination (dpg) with a Leica DM5000 microscope. Differences between means were compared using the Student's $t$-test $(p<0.05)$.

\subsection{Transpiration and Stomatal Conductance}

The transpiration and stomatal conductance were calculated from primary sensor readings of environmental factors, including temperature, relative humidity (RH), atmospheric pressure, and volumetric airflow, using the model 6400-15 Arabidopsis camera adapted to the IRGA LI-6400/XT equipment was used. The diameter of the chamber is $1 \mathrm{~cm}$, and therefore, the area it covers is $0.74 \mathrm{~cm}^{2}$, the leaves used for the measurement 
were intended to cover an area of approximately $0.67 \mathrm{~cm}^{2}$, this camera is designed with transparent windows on the top and bottom of the sheet-covered Propafilm ${ }^{\circledR}$ film for use in natural light, all measurements were made in similar light conditions. An experiment setup was installed to measure the transpiration rate, photosynthesis, and stomatal conductance of 10 seedlings with 15 days post-germination (dpg) from lea13, lea30, and wild-type (WT). Differences between means were compared using the Student's $t$-test $(p<0.05)$.

\subsection{Statistical Analysis}

Statistical analysis was conducted using GraphPad Prism 8.0.1 software. 16 plants were analyzed to evaluate drought, stomatal density, photosynthesis, transpiration, and stomatal conductance. Differences between means were compared using the Student's $t$-test $(p<0.05)$.

\subsection{Microarray Analysis in lea13 Genetic Background}

The microarray procedure was performed by the Microarray Unit of the Institute of Cellular Physiology of the UNAM (http:/ / microarrays.ifc.unam.mx/). This institute has a database of 29,950 genes that make up the complete genome of $A$. thaliana, which allows simultaneous analysis of many genes, yielding quantitative and reproducible data. The analyses were performed in triplicate from RNA extracted from 15 days old cotyledons. The Col-0 ecotype was used as control, and the lea13 line was considered as the variable. The selection of differentially expressed genes was performed with the software genArise (http:/ /www.ifc.unam.mx/genarise/) by calculating the intensity-dependent Z-score. Differentially expressed the NCBI database obtained gene sequences, and the biological processes, molecular functions, and cellular components of upregulated and downregulated genes were examined using the Gene Ontology (GO) database. Functional gene annotation was analyzed with the DAVID tool (http:/ / david.abcc.ncifcrf.gov/). Expression array data are accessible in NCBI's Gene Expression Omnibus with the accession number GSE160866.

Supplementary Materials: The following are available online at https://www.mdpi.com/article/ 10.3390/plants10081694/s1, Figure S1. The average number of the cis-elements. ABRELATERD1 (ACGTG), DRECRTCOREAT (G/ACCGAC), MYBCORE (TAACTG), LTRE1HVBLT49 (CCGAC), and others in Cis elements in the promoter region of Arabidopsis thaliana LEA genes. The promoter regions were analyzed in the $0.5 \mathrm{~kb}$ upstream promoter region of the translation start site using the PLACE database. Figure S2. Schematic drawing of the average number of the cis-elements in the promoter region of Arabidopsis thaliana LEA genes. The promoter region was analyzed in the $0.5 \mathrm{~kb}$ upstream promoter region of the translation start site using the PLACE database. Exons are indicated by black boxes and the location of T-DNA insertions by gray triangles. The various regulatory boxes are shown in different colors. +1 indicates transcript start. Figure S3. Water Content (WC, \%) in rosettes leaves of wild-type, lea13, and lea30 plants. Water content was measured in 10 plants of the wild-type (ecotype Columbia-0), lea13 and lea30 lines after leaving them without watering for 15 days. lea13 and lea30 showed higher water loss compared to the wild-type plants at 10 and 15 days after cessation of irrigation. * Indicates a statistically significant difference at a $95 \%$ confidence level. Figure S4. In silico analysis of LEA13 and LEA30 expression in different plant tissues and stress conditions. Expression of LEA13 and LEA30 based on 20,000 RNA-seq libraries. Expression is measured in FPKM. Figure S5. LEA genes expression on drought conditions in the mutant background. (a) LEA13 expression was analyzed in plants of the lea13 mutant background under drought conditions compared to normal irrigation conditions. LEA13 expression increased under drought conditions in all three tissues analyzed. (b) The same observations were made for $L E A 30$; its expression decreased. In both cases, the increase was more evident in inflorescences. * Indicates a statistically significant difference between control and water deficit conditions at a 95\% confidence level. Figure S6. Expression analysis of LEA genes in different genetic backgrounds. To find out whether the expression of LEA genes can be affected by the expression of another LEA gene. We analyzed the expression of $L E A 13$ in the lea30 background and vice versa. The results showed (a) LEA13 increased its expression in the lea30 background in leaf and stem, but not in inflorescences. (b) LEA30 did not increase its expression concerning wild-type background. * Indicates a statistically 
significant difference between control and water deficit conditions at a 95\% confidence level. Table S1. Primers sequences used in this study.

Author Contributions: Conceptualization, N.-V.D.-F. and G.A.-G.; Data curation, A.L.-C., and G.A.S.-M.; Formal analysis, A.L.-C., H.R.-M., G.-A.S.-M., and G.A.-G.; Funding acquisition, N.-V.D.-F. and G.A.-G.; Investigation, A.L.-C., H.R.-M., G.-A.S.-M., L.G.-C., A.B.-N., W.H.-M., V.M.-T., A.T.-A., J.-G.R.-P., N.-V.D.-F., and G.A.-G.; Methodology, A.L.-C., H.R.-M., L.G.-C., A.B.-N., W.H.-M., V.M.-T., A.T.-A., J.-G.R.-P., and N.-V.D.-F.; Project administration, G.A.-G.; Software, G.-A.S.-M.; Supervision, G.A.-G.; Writing—original draft, A.L.-C. and V.M.-T.; Writing—review and editing, A.L.-C., H.R.-M., L.G.-C., A.B.-N., W.H.-M., J.-G.R.-P., N.-V.D.-F., and G.A.-G. All authors have read and agreed to the published version of the manuscript.

Funding: This research was funded by Tecnológico National de México (TNM), grant number 6412.18-P and 5584.19-P.

Institutional Review Board Statement: Not applicable.

Informed Consent Statement: Not applicable.

Data Availability Statement: The original contributions generated for this study are included in the article and supplementary material. Expression array data are accessible in NCBI's Gene Expression Omnibus with the accession number GSE160866.

Acknowledgments: We acknowledge the Consejo Nacional de Ciencia y Tecnología (CONACYT, México) and Convenio de Desempeño Regional CD-UTA1795, for the scholarship to A.L.-C. and W.H.-M., respectively. This study was performed using the facilities of Tecnológico Nacional de Mexico in Celaya.

Conflicts of Interest: The authors declare no conflict of interest.

\section{References}

1. Wang, W.; Vinocur, B.; Altman, A. Plant responses to drought, salinity and extreme temperatures: Towards genetic engineering for stress tolerance. Planta 2003, 218, 1-14. [CrossRef] [PubMed]

2. Deng, Y.; Srivastava, R.; Quilichini, T.D.; Dong, H.; Bao, Y.; Horner, H.T.; Howell, S.H. IRE1, a component of the unfolded protein response signaling pathway, protects pollen development in Arabidopsis from heat stress. Plant J. 2016, 88, 93-204. [CrossRef]

3. Kim, H.S.; Lee, J.H.; Kim, J.J.; Kim, C.H.; Jun, S.S.; Hong, Y.N. Molecular and functional characterization of CaLEA6, the gene for a hydrophobic LEA protein from Capsicum annuum. Gene 2004, 344, 115-123. [CrossRef] [PubMed]

4. Qin, F.; Shinozaki, K.; Shinozaki, K. Achievements and challenges in understanding plant abiotic stress responses and tolerance. Plant Cell Physiol. 2011, 52, 1569-1582. [CrossRef] [PubMed]

5. Battaglia, M.; Olvera-Carrillo, Y.; Garciarrubio, A.; Campos, F.; Covarrubias, A.A. The enigmatic LEA proteins and other hydrophilins. Plant Physiol. 2008, 148, 6-24. [CrossRef] [PubMed]

6. Wakeel, A.; Wang, L.; Xu, M. SPEECHLESS and MUTE mediate feedback Regulation of Signal Transduction during Stomatal Development. Plants 2021, 10, 432. [CrossRef]

7. Lampard, G.R.; Lukowitz, W.; Ellis, B.E.; Bergmann, D.C. Novel and Expanded Roles for MAPK Signaling in Arabidopsis Stomatal Cell Fate Revealed by Cell Type-Specific Manipulations. Plant Cell 2009, 21, 3506-3517. [CrossRef]

8. Qi, X.; Torii, K.U. Hormonal and environmental signals guiding stomatal development. BMC Biol. 2018, 16, 21. [CrossRef]

9. Hong-Bo, S.; Zong-Suo, L.; Ming-An, S. LEA proteins in higher plants: Structure, function, gene expression and regulation. Colloid Surf. B 2005, 45, 131-135. [CrossRef]

10. Magwanga, R.O.; Lu, P.; Kirungu, J.N.; Lu, H.; Wang, X.; Cai, X.; Zhou, Z.; Zhang, Z.; Salih, H.; Wang, K.; et al. Characterization of the late embryogenesis abundant (LEA) proteins family and their role in drought stress tolerance in upland cotton. BMC Genet. 2018, 15, 19. [CrossRef]

11. Jia, H.; Wang, X.; Shi, Y.; Wu, X.; Wang, Y.; Liu, J.; Fang, Z.; Li, C.; Dong, K. Overexpression of Medicago sativa LEA4-4 can improve the salt, drought, and oxidation resistance of transgenic Arabidopsis. PLoS ONE 2020, 15, e0234085. [CrossRef]

12. Cortez-Baheza, E.; Cruz-Fernández, F.; Hernández-Álvarez, M.I.; Peraza-Luna, F.; Aguado-Santacruz, G.A.; Serratos-Arévalo, J.C.; Ponce, P. A new Lea gene is induced during osmopriming of Capsicum annuum L. seeds. Int. J. Bot. 2008, 4, 77-84. [CrossRef]

13. Acosta-García, G.; Chapa-Oliver, A.M.; Millán-Almaraz, J.R.; Guevara-González, R.G.; Cortez-Baheza, E.; Rangel-Cano, R.M.; Ramírez-Pimentel, J.G.; Cruz-Hernández, A.; Guevara-Olvera, L.; Aguilera-Bibian, J.E.; et al. CaLEA 73 gene from Capsicum annиит L. enhances drought and osmotic tolerance modulating transpiration rate in transgenic Arabidopsis thaliana. Can. J. Plant Sci. 2015, 95, 227-235. [CrossRef]

14. Bies-Ethève, N.; Gaubier-Comella, P.; Debures, A.; Lasserre, E.; Jobet, E.; Raynal, M.; Cooke, R.; Delseny, M. Inventory, evolution and expression profiling diversity of the LEA (late embryogenesis abundant) protein gene family in Arabidopsis thaliana. Plant Mol. Biol. 2008, 67, 107-124. [CrossRef] 
15. Hundertmark, M.; Hincha, D.K. LEA (Late Embryogenesis Abundant) proteins and their encoding genes in Arabidopsis thaliana. BMC Genom. 2008, 9, 118. [CrossRef]

16. Candat, A.; Paszkiewicz, G.; Neveu, M.; Gautier, R.; Logan, D.C.; Avelange-Macherel, M.H.; Macherela, D. The ubiquitous distribution of Late Embryogenesis Abundant proteins across cell compartments in Arabidopsis offers tailored protection against abiotic stress. Plant Cell 2014, 26, 3148-3166. [CrossRef] [PubMed]

17. Huang, K.C.; Lin, W.C.; Cheng, W.H. Salt hypersensitive mutant 9, a nucleolar APUM23 protein, is essential for salt sensitivity in association with the ABA signaling pathway in Arabidopsis. BMC Plant Biol. 2018, 18, 40. [CrossRef] [PubMed]

18. Zhang, H.; Zhang, F.; Yu, Y.; Feng, L.; Jia, J.; Liu, B.; Li, B.; Guo, H.; Zhai, J.A. Comprehensive Online Database for Exploring 20,000 Public Arabidopsis RNA-Seq Libraries. Mol. Plant 2020, 13, 1231-1233. [CrossRef]

19. Cuevas-Velazquez, C.L.; Saab-Rincón, G.; Reyes, J.L.; Covarrubias, A.A. The unstructured N-terminal region of Arabidopsis group 4 Late Embryogenesis Abundant Proteins (LEA) is required for folding and for chaperone-like activity under water deficit. J. Biol. Chem. 2016, 291, 10893-10903. [CrossRef]

20. Bray, E.A. Plant responses to water deficit. Trends Plant Sci. 1997, 2, 48-54. [CrossRef]

21. Yongkun Chen, Y.; Li, C.; Zhang, B.; Yi, J.; Yang, Y.; Kong, C.; Lei, C.; Gong, M. The Role of the Late Embryogenesis-Abundant (LEA) Protein Family in Development and the Abiotic Stress Response: A Comprehensive Expression Analysis of Potato (Solanum Tuberosum). Genes 2019, 10, 148. [CrossRef] [PubMed]

22. Nir, I.; Moshelion, M.; Weiss, D. The Arabidopsis GIBBERELLIN METHYL TRANSFERASE 1 suppresses gibberellin activity, reduces whole-plant transpiration and promotes drought tolerance in transgenic tomato. Plant Cell Environ. 2014, 37, 113-123. [CrossRef] [PubMed]

23. Yoo, C.Y.; Hasegawa, P.M.; Mickelbart, M.V. Regulation of stomatal density by the GTL1 transcription factor for improving water use efficiency. Plant Signal. Behav. 2011, 6, 1069-1071. [CrossRef] [PubMed]

24. Zoulias, N.; Harrison, E.L.; Casson, S.A.; Gray, J.E. Molecular control of stomatal development. Biochem. J. 2018, 475, 441-454. [CrossRef]

25. Xiao, B.; Huang, Y.; Tang, N.; Xiong, L. Over-expression of a LEA gene in rice improves drought resistance under the field conditions. Theor. Appl. Genet. 2007, 115, 35-46. [CrossRef]

26. Dang, N.X.; Popova, A.V.; Hundertmark, M.; Hincha, D.K. Functional characterization of selected LEA proteins from Arabidopsis thaliana in yeast and in vitro. Planta 2014, 240, 325-336. [CrossRef] [PubMed]

27. Tomoki Shibuya, T.; Itai, R.; Maeda, M.; Kitashiba, H.; Isuzugawa, K.; Kato, K.; Kanayama, Y. Characterization of PcLEA14, a Group 5 Late Embryogenesis Abundant Protein Gene from Pear (Pyrus communis). Plants 2020, 9, 1138. [CrossRef] [PubMed]

28. Xu, D.; Duan, X.; Wang, B.; Hong, B.; Ho, T.H.D.; Wu, R. Expression of a Late Embryogenesis Abundant protein gene, HVA7, from barley confers tolerance to water deficit and salt stress in transgenic rice. Plant Physiol. 1996, 110, 249-257. [CrossRef]

29. Salleh, F.M.; Evans, K.; Goodall, B.; Machin, H.; Mowla, S.B.; Mur, L.A.J.; Runions, J.; Theodoulou, F.L.; Foyer, C.H.; Rogers, H.J. A novel function for a redox-related LEA protein (SAG21/AtLEA5) in root development and biotic stress responses. Plant Cell Environ. 2012, 35, 418-429. [CrossRef]

30. Muniz-Pedrosa, A.; Santos-Martins, C.P.; Pereira-Gonçalves, L.; Cardoso-Costa, M.G. Late Embryogenesis Abundant (LEA) Constitutes a Large and Diverse Family of Proteins Involved in Development and Abiotic Stress Responses in Sweet Orange (Citrus sinensis L. Osb.). PLoS ONE 2015, 10, e0145785. [CrossRef]

31. Daszkowska-Golec, A.; Szarejko, I. Open or close the gate-Stomata action under the control of phytohormones in drought stress conditions. Front. Plant Sci. 2013, 4, 138. [CrossRef]

32. Brodribb, T.J.; Sussmilch, F.; McAdam, S.A.M. From reproduction to production, stomata are the master regulators. Plant J. 2020, 101, 756-767. [CrossRef]

33. Yang, X.H.; Li, X.G.; Li, B.L.; Zhang, D.Q. Genome-wide transcriptional profiling reveals molecular signatures of secondary xylem differentiation in Populus tomentosa. Genet. Mol. Res. 2014, 13, 9489-9504. [CrossRef]

34. Richard, O.; Paquet, N.; Haudecoeur, E.; Charrier, B. Organization and Expression of the GSK3/Shaggy Kinase gene family in the moss Physcomitrella patens suggest early gene multiplication in land plants and an ancestral response to osmotic stress. J. Mol. Evol. 2005, 61, 99-113. [CrossRef]

35. Chen, C.; Shu, J.; Li, C.; Thapa, R.K.; Nguyen, V.; Yu, K.; Yuan, Z.C.; Kohalmi, S.E.; Liu, J.; Marsolais, F.; et al. RNA polymerase II-independent recruitment of SPT6L at transcription start sites in Arabidopsis. Nucleic Acids Res. 2019, 47, 6714-6725. [CrossRef]

36. Roxrud, I.; Lid, S.E.; Fletcher, J.C.; Schmidt, E.D.L.; Opsahl-Sorteberg, H.G. GASA4, One of the 14-Member Arabidopsis GASA family of small polypeptides, regulates flowering and seed development. Plant Cell Physiol. 2007, 48, 471-483. [CrossRef]

37. Saibo, N.J.M.; Vriezen, W.H.; Beemster, G.T.S.; Van Der Straeten, D. Growth and stomata development of Arabidopsis hypocotyls are controlled by gibberellins and modulated by ethylene and auxins. Plant J. 2003, 33, 989-1000. [CrossRef] [PubMed]

38. Richardson, L.G.; Torii, K.U. Take a deep breath: Peptide signalling in stomatal patterning and differentiation. J. Exp. Bot. 2013, 64, 5243-5251. [CrossRef]

39. Han, S.K.; Torii, K.U. Lineage-specific stem cells, signals and asymmetries during stomatal development. Development 2016, 143, 1259-1270. [CrossRef] [PubMed]

40. Kim, J.J.; Lee, J.H.; Kim, W.; Jung, H.S.; Huijser, P.; Ahn, J.H. The microRNA156-SQUAMOSA PROMOTER BINDING PROTEINLIKE3 Module Regulates Ambient Temperature-Responsive Flowering via FLOWERING LOCUS T in Arabidopsis. Plant Physiol. 2012, 159, 461-478. [CrossRef] [PubMed] 
41. Chen, X.; Wang, Y.; Lv, B.; Li, J.; Luo, L.; Lu, S.; Zhang, X.; Ma, H.; Ming, F. The NAC family transcription factor OsNAP confers abiotic stress response through the ABA pathway. Plant Cell Physiol. 2014, 55, 604-619. [CrossRef] [PubMed]

42. Pillitteri, L.J.; Dong, J. Stomatal development in Arabidopsis. Arab. Book 2013, 11, e0162. [CrossRef] [PubMed]

43. Ohashi-Ito, K.; Bergmann, D.C. Arabidopsis FAMA controls the final proliferation/differentiation switch during stomatal development. Plant Cell 2006, 18, 2493-2505. [CrossRef]

44. Horstman, A.; Willemsen, V.; Boutilier, K.; Heidstra, R. AINTEGUMENTA-LIKE proteins: Hubs in a plethora of networks. Trends Plant Sci. 2014, 19, 146-157. [CrossRef]

45. Lai, L.B.; Nadeau, J.A.; Lucas, J.; Lee, E.K.; Nakagawa, T.; Zhao, L.; Geisler, M.; Sack, F.D. The Arabidopsis R2R3 MYB proteins FOUR LIPS and MYB88 restrict divisions late in the stomatal cell lineage. Plant Cell 2005, 17, 2754-2767. [CrossRef] [PubMed]

46. Xie, Z.; Li, D.; Wang, L.; Sack, F.D.; Grotewold, E. Role of the stomatal development regulators FLP/MYB88 in abiotic stress responses. Plant J. 2010, 64, 731-739. [CrossRef] [PubMed]

47. Wurzinger, B.; Mair, A.; Pfister, B.; Teige, M. Cross-talk of calcium-dependent protein kinase and MAP kinase signaling. Plant Signal. Behav. 2011, 6, 8-12. [CrossRef]

48. Miwa, H.; Kinoshita, A.; Fukuda, H.; Sawa, S. Plant meristems: CLAVATA3/ESR-related signaling in the shoot apical meristem and the root apical meristem. J. Plant Res. 2009, 122, 31-39. [CrossRef]

49. Lau, O.S.; Davies, K.A.; Chang, J.; Adrian, J.; Rowe, M.H.; Ballenger, C.E.; Bergmann, D.C. Direct roles of SPEECHLESS in the specification of stomatal self-renewing cells. Science 2014, 345, 1605-1609. [CrossRef]

50. Kanaoka, M.M.; Pillitteri, L.J.; Fujii, H.; Yoshida, Y.; Bogenschutz, N.L.; Takabayashi, J.; Zhu, J.K.; Torii, K.U. SCREAM/ICE1 and SCREAM2 specify three cell-state transitional steps leading to Arabidopsis stomatal differentiation. Plant Cell 2008, 20, 1775-1785. [CrossRef]

51. Danzer, J.; Mellott, E.; Bui, A.Q.; Le, B.H.; Martin, P.; Hashimoto, M.; Perez-Lesher, J.; Chen, M.; Pelletier, J.M.; Somers, D.A.; et al Down-regulating the expression of 53 soybean transcription factor genes uncovers a Role for SPEECHLESS in Initiating Stomatal Cell Lineages during Embryo Development. Plant Physiol. 2015, 168, 1025-1035. [CrossRef] [PubMed]

52. MacAlister, C.A.; Ohashi-Ito, K.; Bergmann, D.C. Transcription factor control of asymmetric cell divisions that establish the stomatal lineage. Nature 2007, 445, 537. [CrossRef]

53. MacAlister, C.A.; Bergmann, D.C. Sequence and function of basic helix-loop-helix proteins required for stomatal development in Arabidopsis are deeply conserved in land plants. Evol. Dev. 2011, 13, 182-192. [CrossRef] [PubMed]

54. Weimer, A.K.; Matos, J.L.; Sharma, N.; Patell, F.; Murray, J.A.; Dewitte, W.; Bergmann, D.C. Lineage and stage-specific expressed CYCD7; 1 coordinates the single symmetric division that creates stomatal guard cells. Development 2018, 145, dev160671. [CrossRef] [PubMed]

55. Torii, K.U. Mix-and-match: Ligand-receptor pairs in stomatal development and beyond. Trends Plant Sci. 2012, 17, 711-719. [CrossRef] [PubMed]

56. Herrmann, A.; Torii, K.U. Shouting out loud: Signaling modules in the regulation of stomatal development. Plant Physiol. 2020, 185, 765-780. [CrossRef]

57. Dimmic, M.W.; Rest, J.S.; Mindell, D.P. rtREV: An amino acid substitution matrix for inference of retrovirus and reverse transcriptase phylogeny. J. Mol. Evol. 2002, 55, 65-73. [CrossRef] [PubMed]

58. Kumar, S.; Stecher, G.; Li, M.; Knyaz, C.; Tamura, K. MEGA X: Molecular Evolutionary Genetics Analysis across computing platforms. Mol. Biol. Evol. 2018, 35, 1547-1549. [CrossRef]

59. Kim, J.H.; Kim, W.T. The Arabidopsis RING E3 Ubiquitin Ligase AtAIRP3/LOG2 Participates in Positive Regulation of High-Salt and Drought Stress Responses. Plant Physiol. 2013, 162, 1733-1749. [CrossRef]

60. Yu, S.G.; Cho, N.H.; Kim, J.H.; Oh, T.R.; Kim, W.T. Suppression of DRR1 results in the accumulation of insoluble ubiquitinated proteins, which impairs drought stress tolerance. J. Integr. Plant Biol. 2020, 63, 431-437. [CrossRef] 